\title{
Megastimanes and Ergostane Type Steroid from Leaves Cratylia mollis (Leguminosae)
}

\author{
Luciano S. Lima, ${ }^{a}$ Marcos V. B. Lima, ${ }^{b}$ Juceni P. David, ${ }^{b}$ Ana M. Giulietti, ${ }^{c}$ \\ Luciano P. de Queiroz ${ }^{c}$ and Jorge M. David ${ }^{* a}$
}

\author{
${ }^{a}$ Instituto de Química and ${ }^{b}$ Faculdade de Farmácia, Universidade Federal da Bahia, \\ 40170-290 Salvador-BA, Brazil \\ ${ }^{c}$ Departamento de Ciências Biológicas, Universidade Estadual de Feira de Santana, \\ 44031-460 Feira de Santana-BA, Brazil
}

\begin{abstract}
Do extrato metanólico das folhas de Cratylia mollis, foram isolados através de técnicas cromatográficas, $(3 S, 5 S, 6 S, 9 R)$-3,6-di-hidróxi-5,6-diidro- $\beta$-ionol (1) e um novo nor-isoprenóide identificado como $\left(4 S^{*}, 6 S^{*}\right)$-4-but-1E-enil-4,6-diidróxi-3,5,5-trimetil-ciclo-hex-2-enona (2) além do $5 \alpha, 8 \alpha$-epidioxiergosta-6,22-dien-3- $\beta$-ol. As estruturas foram elucidadas por meio da análise dos dados de EM, IV, $\mathrm{RMN}{ }^{1} \mathrm{H}$ e ${ }^{13} \mathrm{C}$.

From the methanolic extract of the leaves of Cratylia mollis were obtained by chromatographic techniques $(3 S, 5 S, 6 S, 9 R)$-3,6-dihydroxy-5,6-dihydro- $\beta$-ionol (1), and a new bis-norisoprenoid named $\left(4 S^{*}, 6 S^{*}\right)$-4-but-1E-enyl-4,6-dihydroxy-3,5,5-trimethyl-cyclohex-2-enone (2) as well as $5 \alpha, 8 \alpha$-epidioxyergosta-6,22-dien-3- $\beta$-ol. The structures of the pure compounds were elucidated based on MS, ${ }^{1} \mathrm{H}$ and ${ }^{13} \mathrm{C}$ NMR spectroscopic data analyses.
\end{abstract}

Keywords: megastimanes, Leguminosae, Cratylia mollis

\section{Introduction}

Cratylia is one of 670 genera belonging to Leguminosae family, ${ }^{1}$ it is included in the Phaseolae tribe (subtribe Diocleinae $)^{2}$ and this position is maintained until the most recent classifications. ${ }^{3}$ This genus comprises only five species, C. argentea (Desvaux) O. Kuntze, C. bahiensis L. P. de Queiroz, $C$. hypargyrea Martius ex Benth., $C$. intermedia (Hassler) L. P. de Queiroz and C. mollis Martius ex Benth. From chemical point of view the subtribe genera can be characterized by the presence of the non-proteic aminoacids, especially canavanine. ${ }^{4}$ However, there are no data of the occurrence of this aminoacid in Cratylia species. On the other hand, other chemical characteristic of Cratylia is the presence of lectins in their seeds which shows great similarity with the lectins isolated from seeds of other species of same tribe. ${ }^{5}$

Cratilya mollis is a legume shrub native to the Northeast semi-arid region of Brazil, especially in "caatinga". This species is popularly known as "camaratuba" or "camaratu"

\footnotetext{
*e-mail: jmdavid@ufba.br
}

and is highly resistant to desiccation. The leaves have been an alternative source of nutrition for cattle, being recommended to be employed by locals as forage to improve cattle's nutrition, especially during the dry seasons, contributing to regional development of the semi-arid. ${ }^{6}$ However, in spite of studies the about of the biological activities of this and related species ${ }^{7}$ to date there are no phytochemical studies regarding $C$. mollis.

In the present work it is described the phytochemical study of leaves of Cratylia mollis led to isolation of two bis-norisoprenoids (1 and $\mathbf{2}$ ) besides the $5 \alpha, 8 \alpha$ epidioxyergosta-6,22-dien-3- $\beta$-ol (3).

\section{Results and Discussion}

The $\mathrm{C}_{13}$-norisoprenoid (1) is known as 3,6-dihydroxy5,6-dihydro- $\beta$-ionol. It was identified by analysis of ESIMS, IR, optical rotation, ${ }^{1} \mathrm{H}$ and ${ }^{13} \mathrm{C}$ NMR and comparison with data previously published in the literature. ${ }^{8}$ Moreover, HMQC, HMBC and COSY spectra permitted to attribute unequivocally all the NMR signals. The ${ }^{13} \mathrm{C}$ NMR data of $\mathbf{1}$ are compatible with that previously described for 
<smiles>CC(O)C=C[C@]1(O)C(C)C[C@H](O)C[C@]1(C)I</smiles>

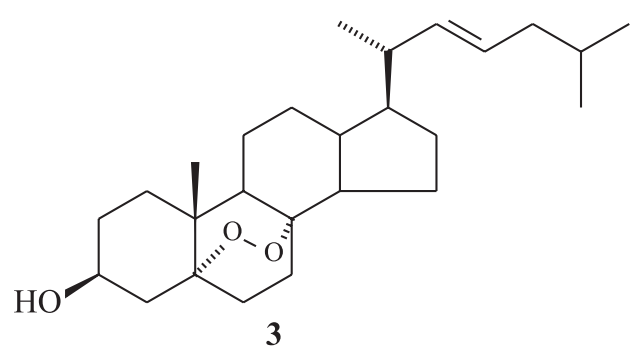<smiles>CC/C=C/[C@@]1(O)C(C)=CC(=O)C(O)C1(C)C</smiles>

2<smiles>[R]C1C(=O)C=C(C)[C@](O)(/C=C/C(C)OC)C1(C)C</smiles>

Figure 1. Isolates of leaves of Cratylia mollis and other megastimanes.

(3S,5R,6S,9R)-3,6-dihydroxy-5,6-dihydro- $\beta$-ionol obtained from Apollonias barbujana (Lauraceae) ${ }^{8}$ except for C-1. However, the HMQC and HMBC of $\mathbf{1}$ permitted to attribute the peak at $\delta 16.4$ to $\mathrm{C}-13$ by the observed correlations of one doublet at $\delta 0.79$ and this carbon in the HMQC and C-4 $(\delta$ $39.9)$ and $\mathrm{C}-6(\delta$ 78.1) observed in the HMBC experiment. This findings permitted to determinate an axial position of $\mathrm{CH}_{3}-13$ instead of equatorial as previously proposed and, concluded compound $\mathbf{1}$ is $(3 S, 5 S, 6 S, 9 R)$-3,6-dihydroxy-5,6dihydro- $\beta$-ionol. Thus, it is a must a revision of ${ }^{13} \mathrm{C} N M R$ data and structure of the megastimane isolated from A. barbujana.

The ${ }^{13} \mathrm{C}$ NMR spectra (including DEPT experiments) of 2 showed signals were assigned to four methyls, four methines, one methylene and four non-hydrogenated carbons. These findings besides the protoned molecular ion $[\mathrm{M}-\mathrm{H}]^{+}$observed at $\mathrm{m} / \mathrm{z} 223.1330$ in the negative
HRESIMS permitted to propose molecular formula $\mathrm{C}_{13} \mathrm{H}_{20} \mathrm{O}_{3}$ (requires 223.1334) which was indicative of a $\mathrm{C}_{13}$-norisoprenoid derivative. The signals at $\delta 198.5,126.7$ and 163.4 observed in the ${ }^{13} \mathrm{C}$ NMR spectra, and the singlet at $\delta 5.95$ in the ${ }^{1} \mathrm{H}$ NMR spectra were indicative of presence of a $\alpha, \beta$-unsaturated ketone group. These findings together with the additional chemical shifts indicated the structural similarity of $\mathbf{2}$ and the known megastigmane glycosides 4 and 5. ${ }^{9}$ The HMQC spectrum was elucidative once it permitted to identify the correlations of closer hydrogen signals with respective carbon resonances. However, the analysis of HMBC spectral data was conclusive to confirm the structure of compound 2 . Briefly, the correlations of H-4 $(\delta 5.95), \mathrm{H}-7(\delta 5.79)$ and the C-6 $(\delta$ 78.9) and, H-10 $(\delta$ $1.22)$ and $\mathrm{C}-9(\delta 49.6)$ and $\mathrm{C}-8(\delta$ 135.6) were indicative the $E$-butenyl group is attached at C-6 (Table 1).

Table 1. ${ }^{1} \mathrm{H}$ and ${ }^{13} \mathrm{C}$ NMR assignments for the compounds 1 and $2(500 / 300$ and $125 / 75 \mathrm{MHz})$

\begin{tabular}{|c|c|c|c|c|c|}
\hline \multirow[b]{2}{*}{ Position } & \multicolumn{2}{|c|}{$\mathbf{1}^{\mathrm{a}}$} & \multicolumn{3}{|c|}{$2^{\mathrm{b}}$} \\
\hline & $\delta_{\mathrm{H}}$ & $\delta_{\mathrm{C}}$ & $\delta_{\mathrm{H}}$ & $\delta_{\mathrm{C}}$ & $\operatorname{HMBC}(\mathrm{H} \rightarrow \mathrm{C})$ \\
\hline 1 & - & 40.5 & - & 41.1 & - \\
\hline 2 & $\begin{array}{l}1.65(\mathrm{~m}) \\
1.40(\mathrm{~m})\end{array}$ & 45.9 & $4.38(\mathrm{~m})$ & 68.0 & - \\
\hline 3 & $3.78(\mathrm{~m})$ & 67.4 & - & 198.5 & - \\
\hline 4 & $\begin{array}{l}1.65(\mathrm{~m}) \\
1.40(\mathrm{~m})\end{array}$ & 39.9 & $5.95(\mathrm{~s})$ & 126.7 & C-6 \\
\hline 5 & $1.95(\mathrm{~m})$ & 35.4 & - & 163.4 & - \\
\hline 6 & - & 78.1 & - & 78.9 & - \\
\hline 7 & $5.52(\mathrm{~d}, 15.6)$ & 135.4 & $5.79(\mathrm{~d}, 15.6)$ & 129.0 & C- $6, C-13$ \\
\hline 8 & $5.69(\mathrm{dd}, 15.6,6.3)$ & 133.8 & 5.81 (ddd, 15.6, indt, indt) & 135.6 & - \\
\hline 9 & $4.40(\mathrm{~m})$ & 69.1 & $\begin{array}{l}2.43 \text { (ddt, } 8.1, \text { indt, indt }) \\
2.37 \text { (ddt, 8.1, 6.6) }\end{array}$ & 49.6 & - \\
\hline 10 & $1.23(\mathrm{~d}, 6.3)$ & 24.1 & $1.22(\mathrm{t}, 6.6)$ & 23.6 & C-8, C-9 \\
\hline 11 & $0.97(\mathrm{~s})$ & 25.3 & $0.92(\mathrm{~s})$ & 23.9 & $\mathrm{C}-2$ \\
\hline 12 & $0.83(\mathrm{~s})$ & 25.2 & $0.95(\mathrm{~s})$ & 22.8 & $\mathrm{C}-2$ \\
\hline 13 & $0.79(\mathrm{~d}, 6.9)$ & 16.4 & $1.90(\mathrm{~s})$ & 19.1 & $\mathrm{C}-2, \mathrm{C}-3, \mathrm{C}-4$ \\
\hline
\end{tabular}

${ }^{\mathrm{a}}$ Recorded in $\mathrm{CD}_{3} \mathrm{OD}$; ${ }^{\mathrm{b}} \mathrm{CDCl}_{3}$; multiplicities obtained using DEPT experiments. 
The relative configuration of compound $\mathbf{2}$ was determinate by phase-sensitive NOESY, once the spatial interactions of $\mathrm{H}-7$ and $\mathrm{H}-2$ were indicative the butenyl group and $\mathrm{H}-2$ were in same face (Figure 2). The proposed relative stereochemistry was also confirmed by analysis of coupling constant of derivative $\mathbf{2 a}$, obtained as main product of reduction of 2 by $\mathrm{NaBH}_{4} / \mathrm{MeOH}$. The ${ }^{1} \mathrm{H}$ NMR spectrum of 2a showed the peak of $\mathrm{H}-3$ as a double doublet at $\delta 3.4(\mathrm{~J}$ $12.96 .5 \mathrm{~Hz}$ ) revealing pseudodiaxial coupling of $\mathrm{H}-3$ and $\mathrm{H}-2$, which allowed to confirm the relative configuration of compound 2 .

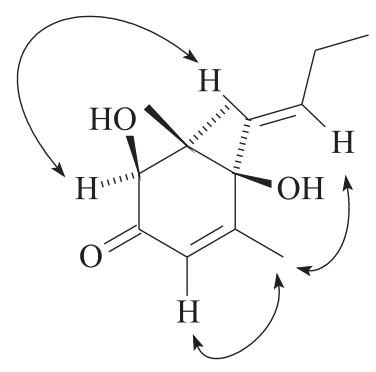

Figure 2. The NOESY correlations of compound 2.

The APCI-MS, ${ }^{1} \mathrm{H}$ NMR and ${ }^{13} \mathrm{C}$ NMR spectra of compound $\mathbf{3}$ and comparison with data previously describe in literature ${ }^{10}$ permitted to identify this steroid. However correlations observed in COSY, HMQC and $\mathrm{HMBC}$ experiments indicated the values of ${ }^{13} \mathrm{C}$ NMR data previously established for C-6 and C-7 must be changed.

This is the first occurrence of the megastimane 4-but1-enyl-4,6-dihydroxy-3,5,5-trimethyl-cyclohex-2-enone (2). Compound $\mathbf{1}$ was previously isolated from Apollonias barbujana (Lauraceae) ${ }^{8}$ but this is the first time it is being reported in Leguminosae family. Compound $\mathbf{3}$ was previously isolated from fungus Lactarium volemus, Schinopsis brasiliensis and Typha latifolia. ${ }^{10}$ However the detailed analysis of correlations observed in HMQC and HMBC experiments permitted to attribute unequivocally the C-13 NMR data for this steroid.

\section{Experimental}

\section{General procedures}

${ }^{1} \mathrm{H}(300 \mathrm{MHz}) ;{ }^{13} \mathrm{C}$ NMR and DEPT $(75 \mathrm{MHz})$ experiments were carried out in a Varian mod. Gemini 2000. HMQC, NOESY and HMBC were run on a Varian INOVA 500: chemical shifts were recorded in $\delta$ (ppm) from the solvent peak relative to TMS; APCI and ESIMS were obtained on Shimadzu LCMS-2010; HRESIMS was recorded on Bruker micrOTOF II, IR spectra were taken on a Varian mod. 640-IR spectrophotometer and optical rotations were measured with a Perkin Elmer polarimeter mod. 341.

Column chromatography was carried out on silica gel 60 (Akros 0.04-0.073 mm) and, silica gel TLC plates were used to monitor the chromatographic fractionment employing iodine fumes, Libermann-Bouchard spray reagent, and UV light (254/366 nm).

\section{Plant material}

Botanical material of $C$. mollis was collected at Jacobina, Bahia State, a region where "caatinga" vegetation is prevalent. A voucher is deposited at Herbarium of Universidade Estadual de Feira de Santana under number LP5119.

\section{Extraction and isolation}

The powdered leaves $(4.1 \mathrm{Kg})$ were repeatedly extracted with $\mathrm{MeOH}$ at room temperature. The leaf crude extract was immediately partitioned with $\mathrm{CHCl}_{3} / \mathrm{MeOH}: \mathrm{H}_{2} \mathrm{O}$ (6:4), and after the evaporation of $\mathrm{CHCl}_{3}$ under vacuum, the extract (73.2 g) obtained was partitioned with hexane/MeOH: $\mathrm{H}_{2} \mathrm{O}$ (9:1). The hydromethanolic partition phase (28.89 g) was submitted to CC using Silica gel as adsorvent and eluted with mixtures $\mathrm{CHCl}_{3}: \mathrm{MeOH}$ with gradient of polarity $(95: 5 \rightarrow 3: 2)$. The fractions ( $1.88 \mathrm{~g}$ ) eluted with $\mathrm{CHCl}_{3}: \mathrm{MeOH}$ (9:1) were jointed and submitted to another $\mathrm{CC}$ on silica gel which was eluted with mixtures of $\mathrm{CHCl}_{3}: \mathrm{MeOH}$ (95:5 and 9:1). The fractions $(88.8 \mathrm{mg}$ ) eluted with the system $\mathrm{CHCl}_{3}: \mathrm{MeOH}$ (95:5) were subjected to PTLC and developed with a mixture of $\mathrm{CHCl}_{3}: \mathrm{MeOH}: \mathrm{HOAc}$ (90:9:1). This procedure permitted to obtain compound $\mathbf{1}(15.0 \mathrm{mg})$. The fractions $(175 \mathrm{mg})$ eluted with $\mathrm{CHCl}_{3}: \mathrm{MeOH}(9: 1)$ were rechromatographed on Sephadex LH-20 column with $\mathrm{Hex}: \mathrm{CH}_{2} \mathrm{Cl}_{2}$ (2:8) as eluent to yield compound 2 (25.0 mg).

The hexane partition phase (42.9 g) was submitted to a CC on Si gel 60 with mixtures of Hex:EtOAc. The fractions ( $4.5 \mathrm{~g})$ eluted with Hex:EtOAc (95:5) were further submitted to a flash $\mathrm{CC}$ on silica gel eluted with $\mathrm{CHCl}_{3}: \mathrm{MeOH}$ (98:2) affording compound 3 (7.2 mg).

(1S,4S,6S)-1-(3-Hydroxy-but-1E-enyl)-2,2,6-trimethylcyclohexane-1,4-diol or (3S,5S,6S,9R)-3,6-Dihydroxy-5,6dihydro- $\beta$-ionol (1)

Colorless syrup. $[\alpha]_{\mathrm{D}}^{20}-7.0^{\circ}(c 0.48, \mathrm{MeOH}),{ }^{1} \mathrm{H}$ and ${ }^{13}$ C NMR: Table 1.

(4S*, 6S*)-4-But-1E-enyl-4,6-dihydroxy-3,5,5-trimethylcyclohex-2-enone (2)

Oil. $[\alpha]_{\mathrm{D}}^{20}+56.0^{\circ}(c$ 1.47, $\mathrm{MeOH}) \operatorname{ESIMS}(m / z) 223$ 
$[\mathrm{M}-\mathrm{H}]^{-}$, and $255[\mathrm{M}-\mathrm{H}+\mathrm{MeOH}], \mathrm{IR} v_{\max } / \mathrm{cm}^{-1}: 3200-3600$ $(\mathrm{OH}), 1713(\mathrm{C}=\mathrm{O}), 1656(\mathrm{C}=\mathrm{C}),{ }^{1} \mathrm{H}$ and ${ }^{13} \mathrm{C}$ NMR: Table 1.

\section{Reaction of reduction of compound 2}

Compound $2(5 \mathrm{mg})$ was dissolved em $\mathrm{MeOH}(2.0 \mathrm{~mL})$ and added a suspension containing $\mathrm{NaBH}_{4}$ in $\mathrm{MeOH}$. The mixture was stirred at room temperature during $30 \mathrm{~min}$. After the solvent was evaporated the residue was dissolved in $\mathrm{CHCl}_{3}$ and $\mathbf{2 a}(3.5 \mathrm{mg})$ was obtained.

\section{Acknowledgments}

The authors are grateful to Conselho Nacional de Desenvolvimento Científico e Tecnológico (CNPq, Brazil), IMSEAR (CNPq/MCT), FAPESB and Fundação Coordenação de Aperfeiçoamento de Pessoal de Nível Superior (CAPES) for fellowship support and grants.

\section{Supplementary Information}

Supplementary information for compounds $\mathbf{1 - 3}$ is available free of charge at http://jbcs.sbq.org.br, as a PDF file.

\section{References}

1. Joly, A. B.; Botânica- Introdução à Taxonomia Vegetal, Cia Editora Nacional: São Paulo, Brasil, 1998.

2. Bentham, G.; Commentationes de Leguminosarum Generibus, Sollingeri, J. B., ed., Vienna, 1837.
3. Hutchinson, J.; The Genera of Flowering Plants, vol. 1, Claredon Press: Oxford, 1964; Baudet, J. C.; Bull. Jard. Bot. Nat. Belg. 1978, 48, 183; Lackey, J. A. In Advances in Legume Systematics, part 1, Polhill, R. M.; Raven, P. H., eds., Kew Royal Botanic Gardens: England, 1981.

4. Turner, B. L.; Harborne, J. B.; Phytochemistry 1967, 6, 863.

5. Moreira, R. A.; Barros A. C. H.; Oliveira, J. T. A.; Braz. Arch. Biol. Technol. 1985, 28, 172.

6. Paiva, P. M. G.; Oliva; M. L. V.; Fritz, H.; Coelho, L. C. B. B.; Sampaio, C. A. M.; Phytochemistry 2006, 67, 545.

7. Andrade, C. A. S.; Correia, M. T. S.; Coelho, L. C. B. B.; Nascimento, S. C.; Santos-Magalhães, N. S.; Int. J. Pharm. 2004, 278, 435; Maciel, E. V. M.; Araujo-Filho, V. S.; Nakazawa, M.; Gomes, Y. M.; Coelho, L. C. B. B.; Correia, M. T. S.; Biologicals 2004, 32, 57; Paiva, P. M. G.; Souza, A. F.; Oliva, M. L. V.; Kennedy, J. F.; Cavalcanti, M. S. M.; Coelho, L. C. B. B.; Sampaio, C. A. M.; Bioresour. Technol. 2003, 88, 75; Barreiros, A. L. B. S.; David, J. P.; Queiroz, L. P. de; David, J. M.; Phytochemistry 2000, 55, 805.

8. Wirth, J.; Guo, W.; Baumes, R.; Gunata, Z.; J. Agric. Food Chem. 2001, 49, 2917; Perez, C.; Trujillo, J.; Almonacid, L. N.; Trujillo, J.; Navarro E.; Alonso, S. J.; J. Nat. Prod. 1996, $59,69$.

9. Kanchanapoom, T.; Chumsri, P.; Kasai, R.; Otsuka, H.; Yamasaki, K.; Phytochemistry 2003, 63, 985.

10. Yue, J-M.; Chen, S-M.; Lin, Z-W.; Phytochemistry 2001, 56, 801; Cardoso, M. P.; David, J. M.; David, J. P.; Nat. Prod. Res. 2005, 19, 431; Greca, M. D.; Mangoni, L.; Molinaro, A.; Monaco, P.; Previtera, L.; Gazz. Chim. Ital. 1990, 120, 391.

Received: November 25, 2008 Web Release Date: September 28, 2009 


\section{Megastimanes and Ergostane Type Steroid from Leaves Cratylia mollis (Leguminosae)}

Luciano S. Lima, ${ }^{a}$ Marcos V. B. Lima, ${ }^{b}$ Juceni P. David, ${ }^{b}$ Ana M. Giulietti, ${ }^{c}$ Luciano P. de Queiroz ${ }^{c}$ and Jorge M. David ${ }^{* a}$

${ }^{a}$ Instituto de Química and ${ }^{b}$ Faculdade de Farmácia, Universidade Federal da Bahia, 40170-290 Salvador-BA, Brazil

${ }^{c}$ Departamento de Ciências Biológicas, Universidade Estadual de Feira de Santana, 44031-460 Feira de Santana-BA, Brazil

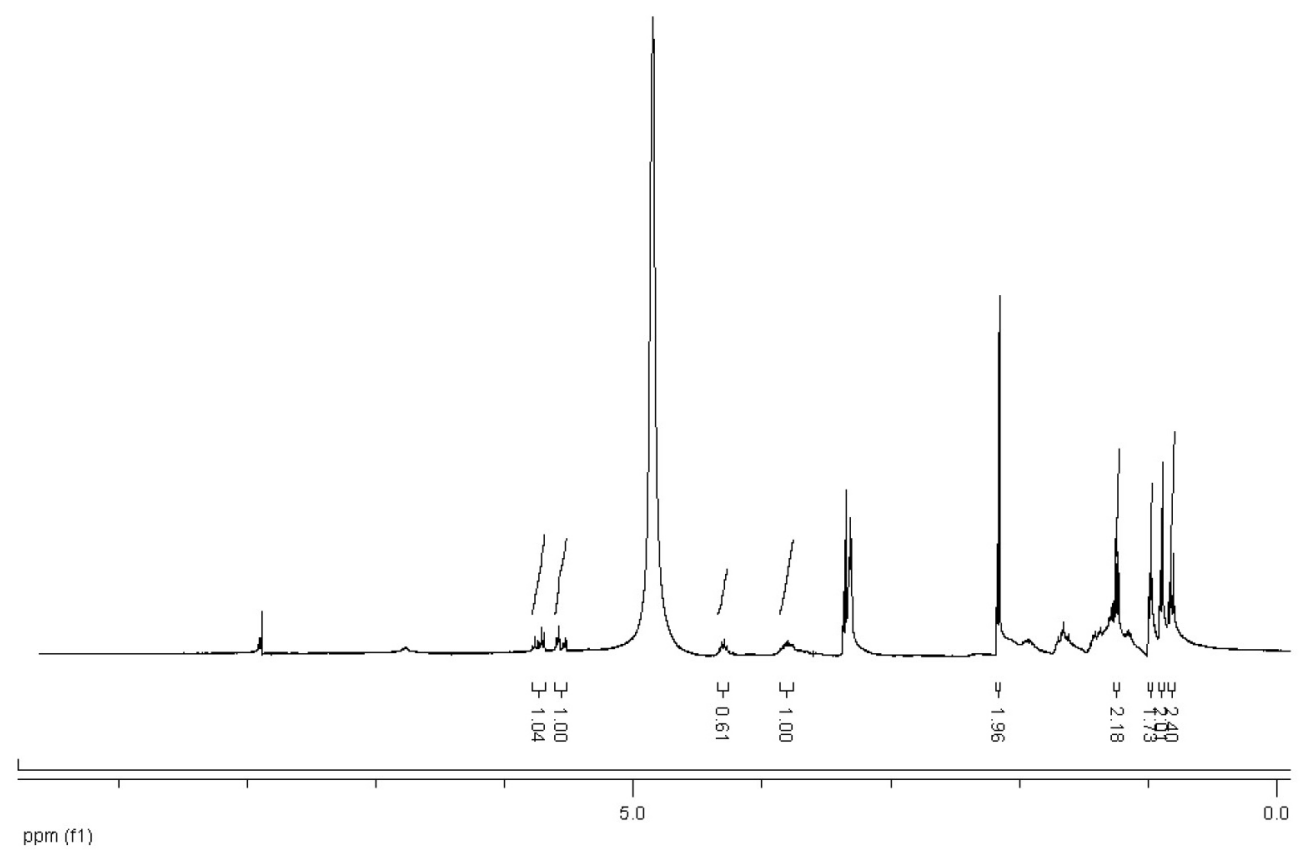

Figure S1. ${ }^{1} \mathrm{H}$ NMR spectrum of compound $\mathbf{1}\left(\mathrm{CD}_{3} \mathrm{OD}, 300 \mathrm{MHz}\right)$. 

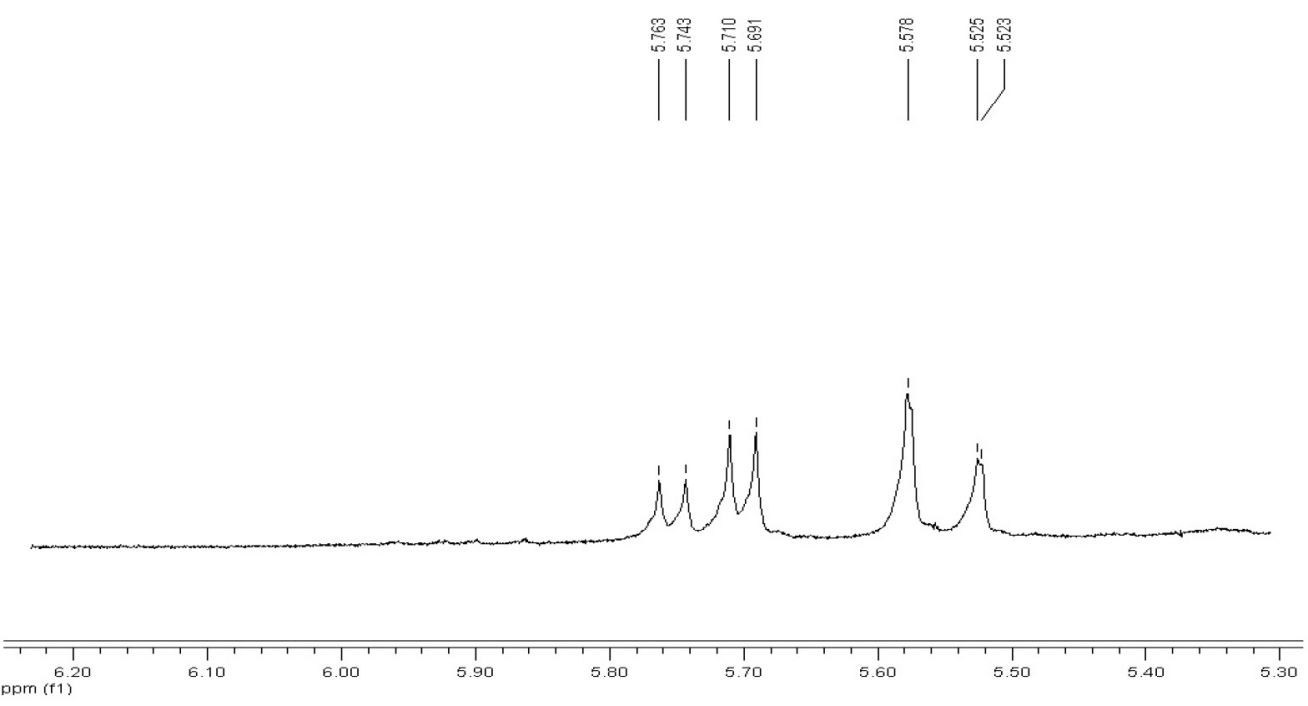

Figure S2. Expansion of ${ }^{1} \mathrm{H}$ NMR spectrum of compound $\mathbf{1}\left(\mathrm{CD}_{3} \mathrm{OD}, 300 \mathrm{MHz}\right)$.

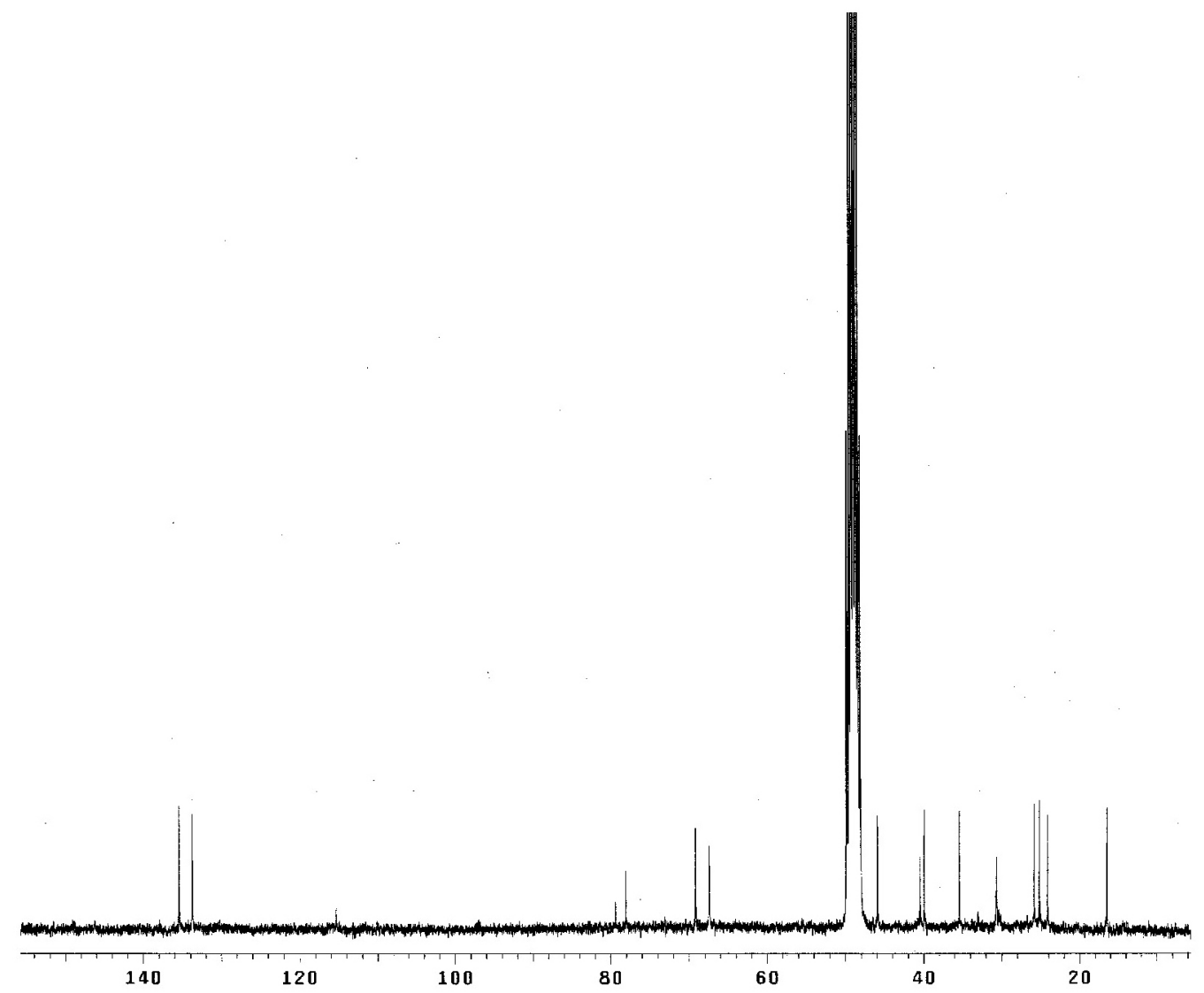

Figure S3. ${ }^{13} \mathrm{C}$ spectrum of compound $\mathbf{1}\left(\mathrm{CD}_{3} \mathrm{OD}, 75 \mathrm{MHz}\right)$. 


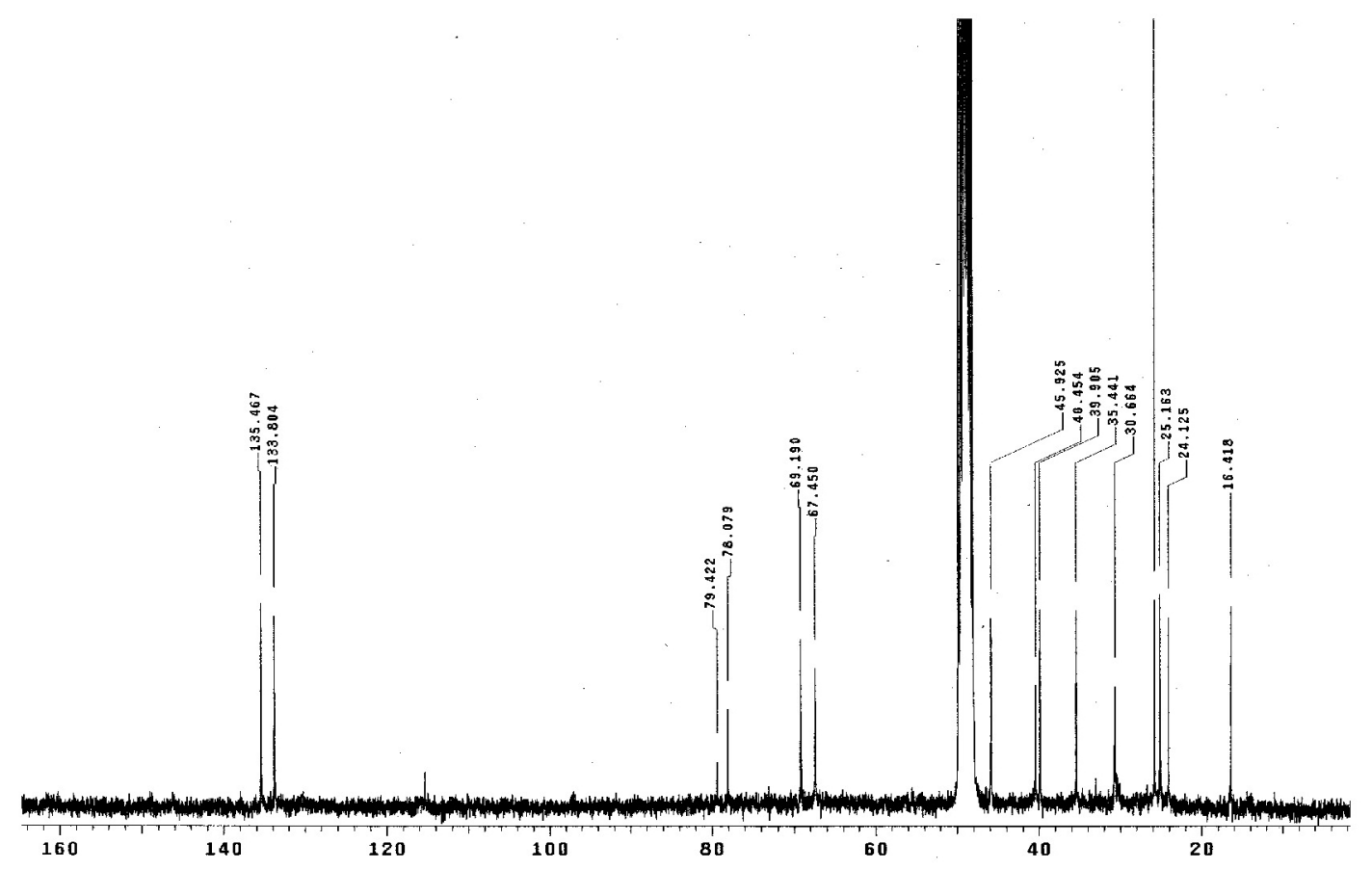

Figure S4. Expansion of ${ }^{13} \mathrm{C}$ NMR spectrum of compound $\mathbf{1}\left(\mathrm{CD}_{3} \mathrm{OD}, 75 \mathrm{MHz}\right)$. 
A

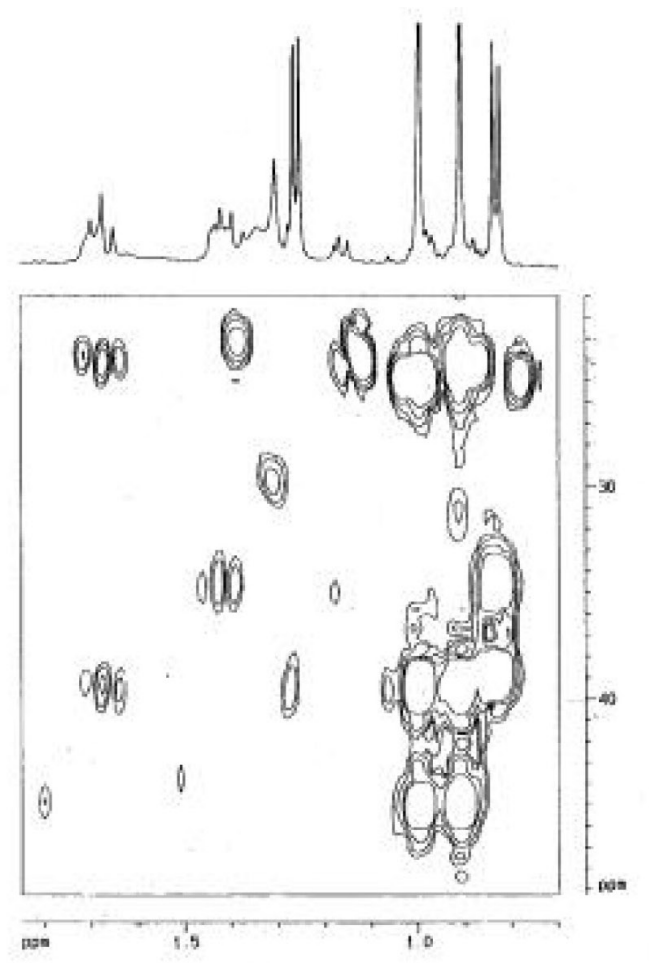

B

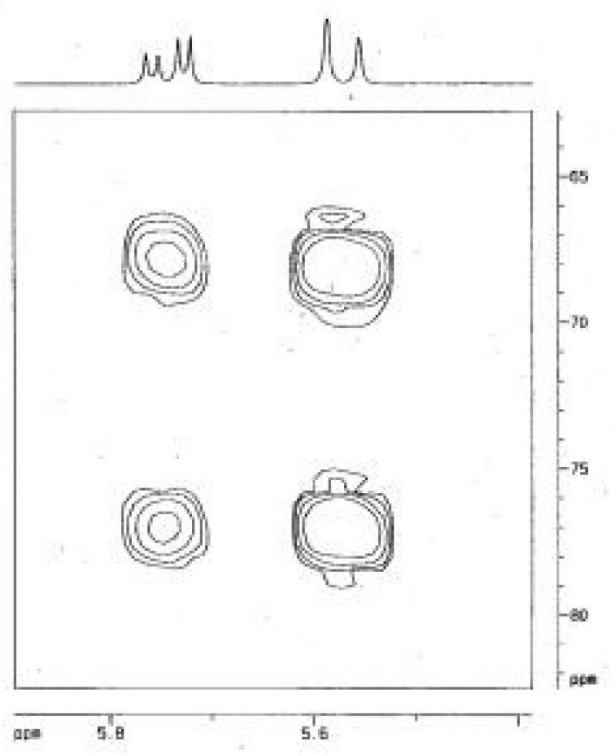

Figure S5. Expansions of the gHMBC spectrum of compound $\mathbf{1}\left(\mathrm{CD}_{3} \mathrm{OD}\right.$, $500 \mathrm{MHz})$.
A

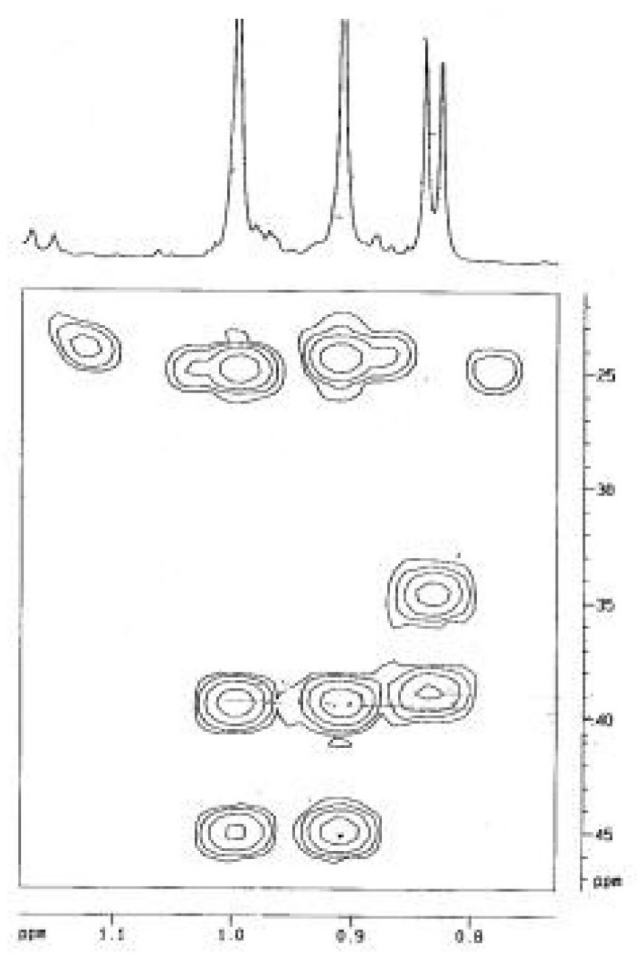

B

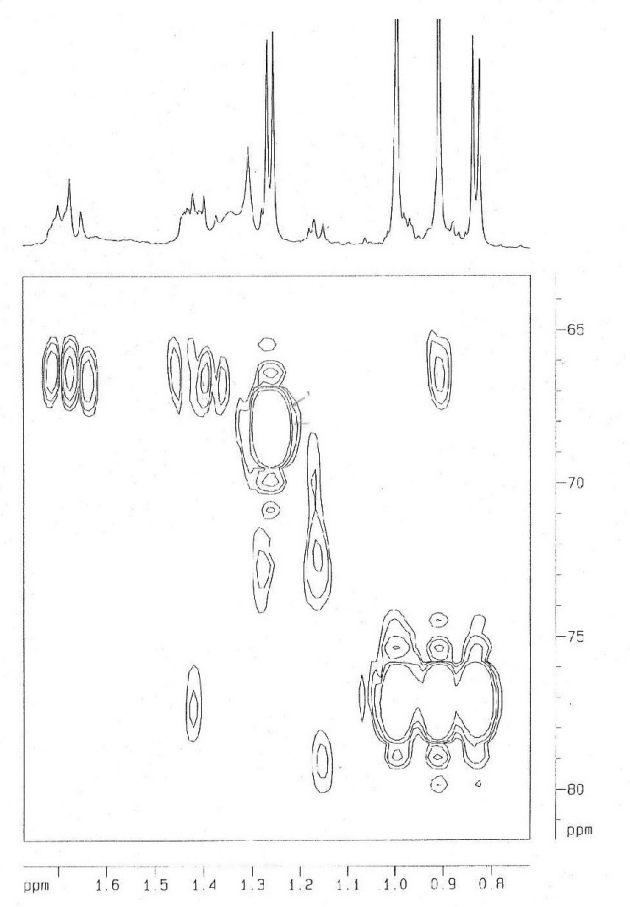

Figure S6. Expansion of the HMBCGS spectrum of compound $\mathbf{1}\left(\mathrm{CD}_{3} \mathrm{OD}\right.$, $500 \mathrm{MHz})$. 


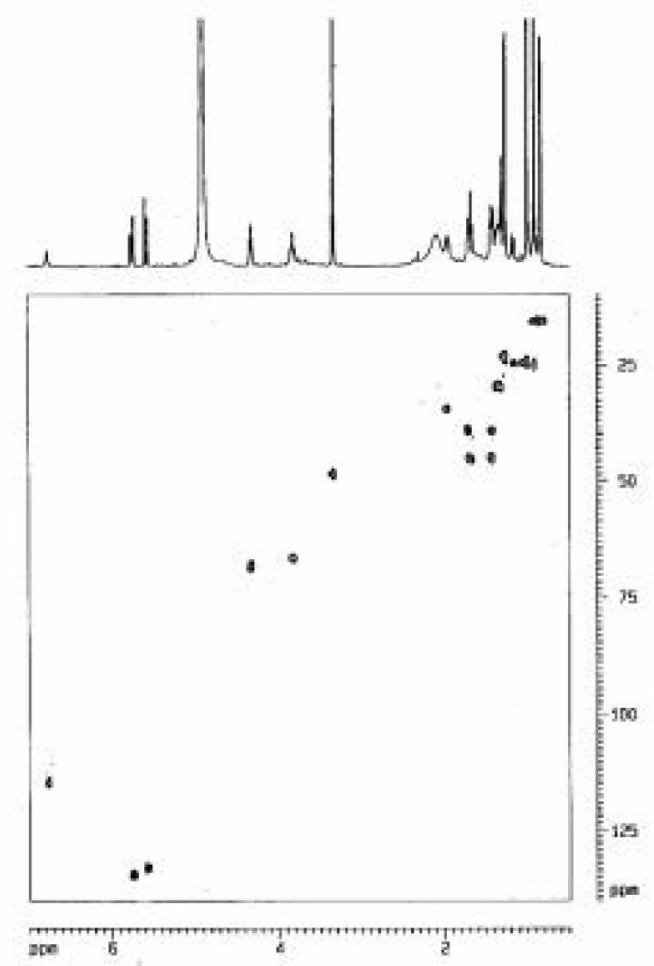

Figure S7. gHMQC spectrum of compound $1\left(\mathrm{CD}_{3} \mathrm{OD}, 500 \mathrm{MHz}\right)$.

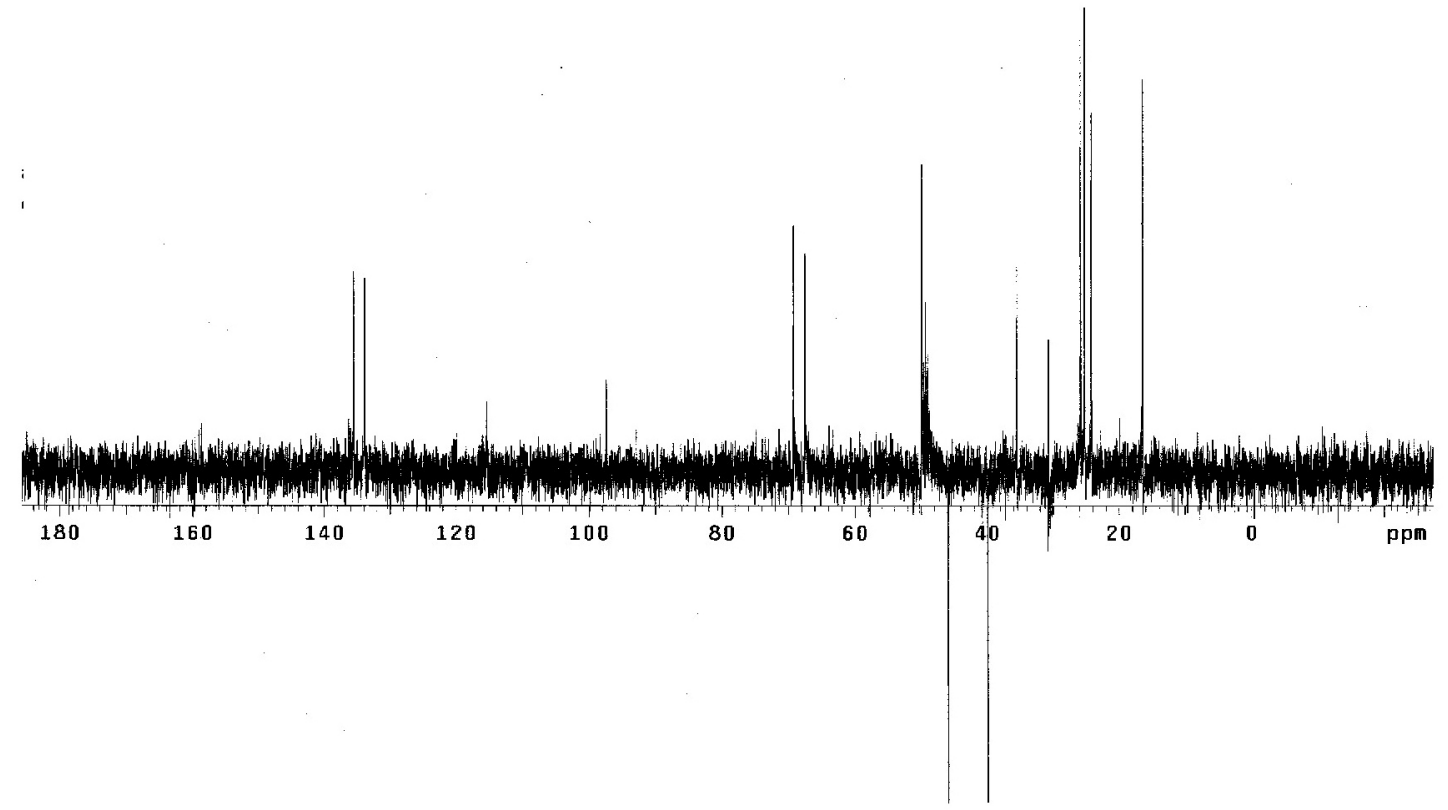

Figure S8. DEPT $135^{\circ}$ spectrum of compound $\mathbf{1}\left(\mathrm{CD}_{3} \mathrm{OD}, 75 \mathrm{MHz}\right)$. 


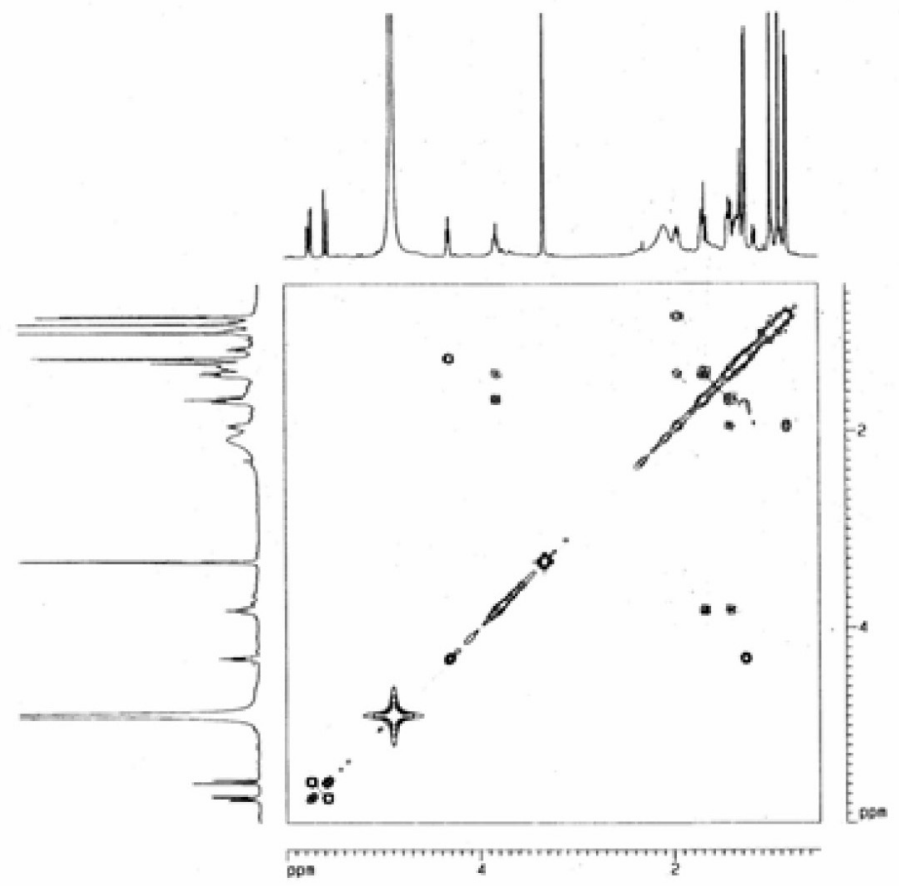

Figure S9. COSYGS spectrum of compound $\mathbf{1}\left(\mathrm{CD}_{3} \mathrm{OD}, 500 \mathrm{MHz}\right)$.

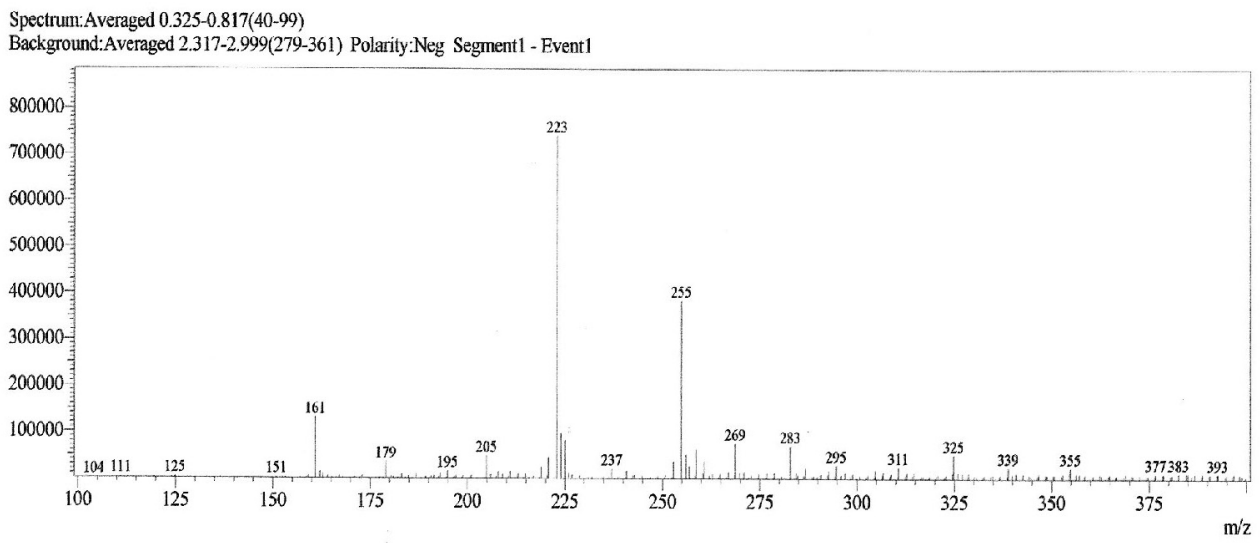

Figure S10. Low resolution negative APCIMS of compound 2. 


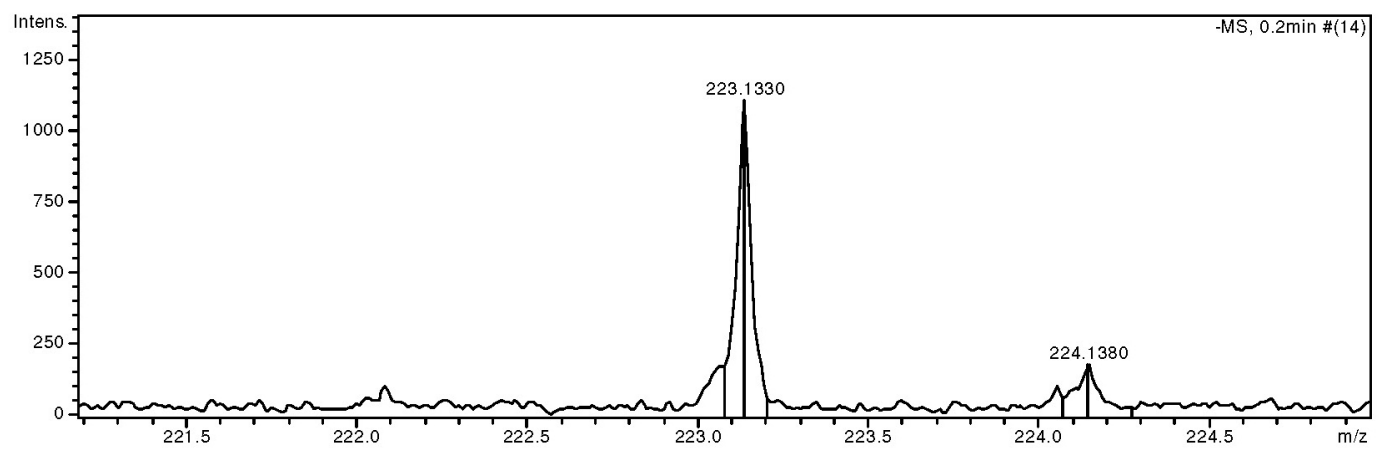

Figure S11. Negative HRESIMS of compound 2.

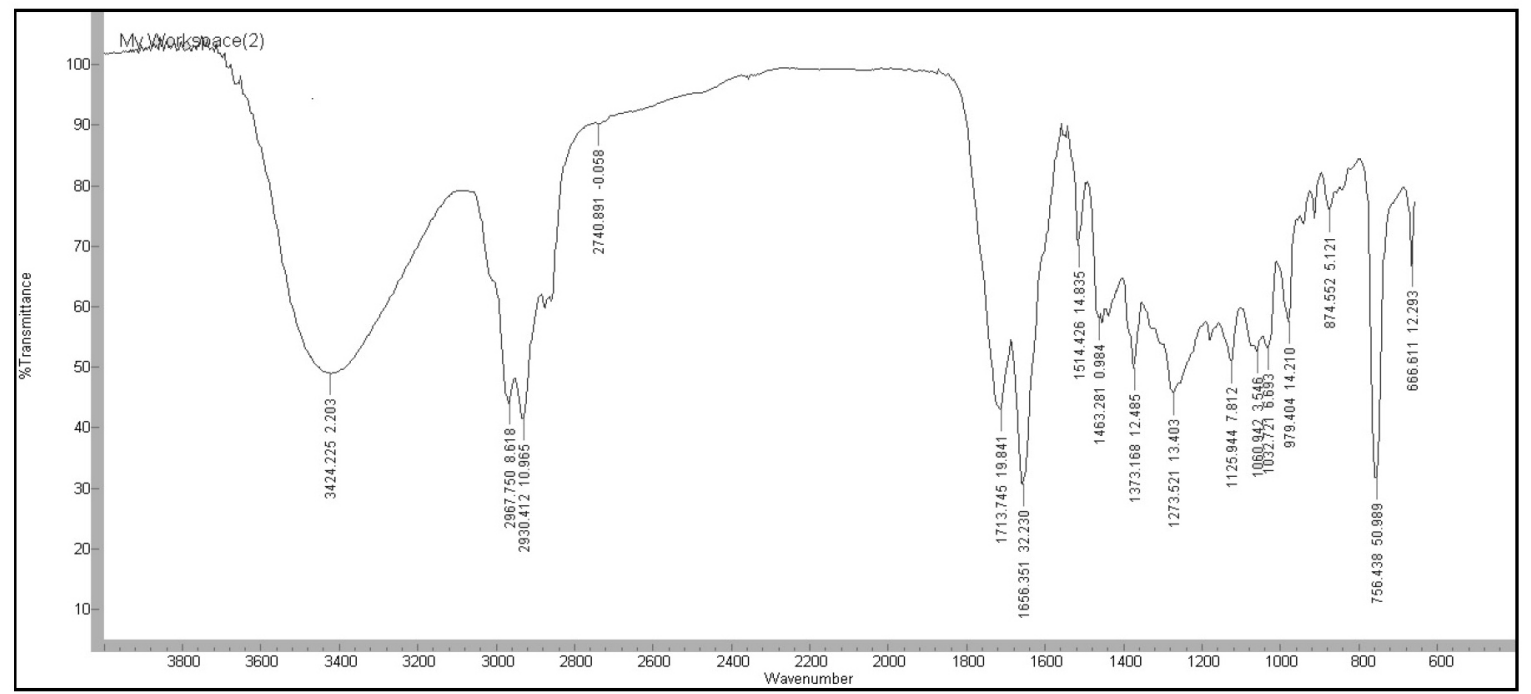

Figure S12. IR spectrum of compound 2 (film).

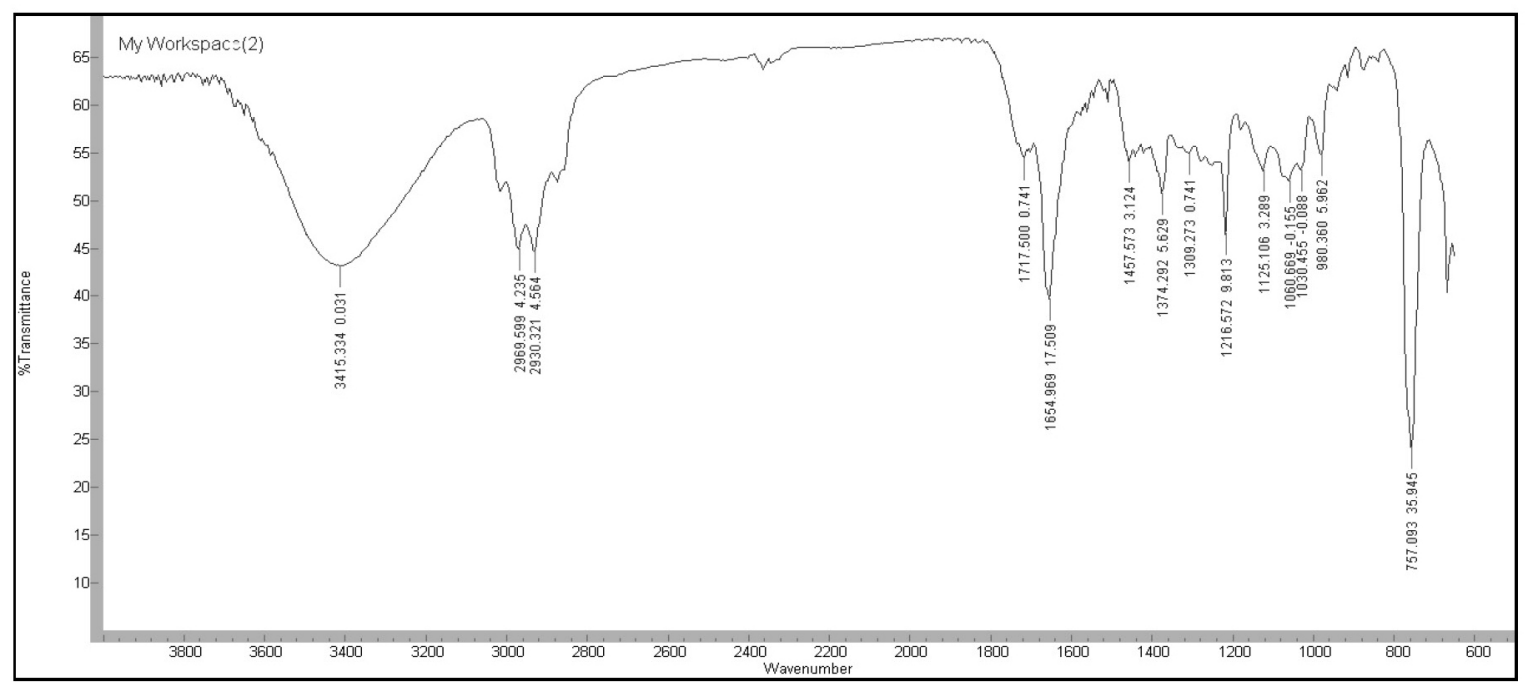

Figure S13. IR spectrum of product reduction of compound 2 (film). 


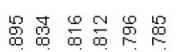

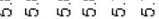

$(1) 1)$

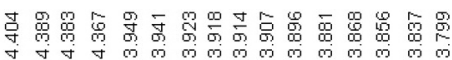
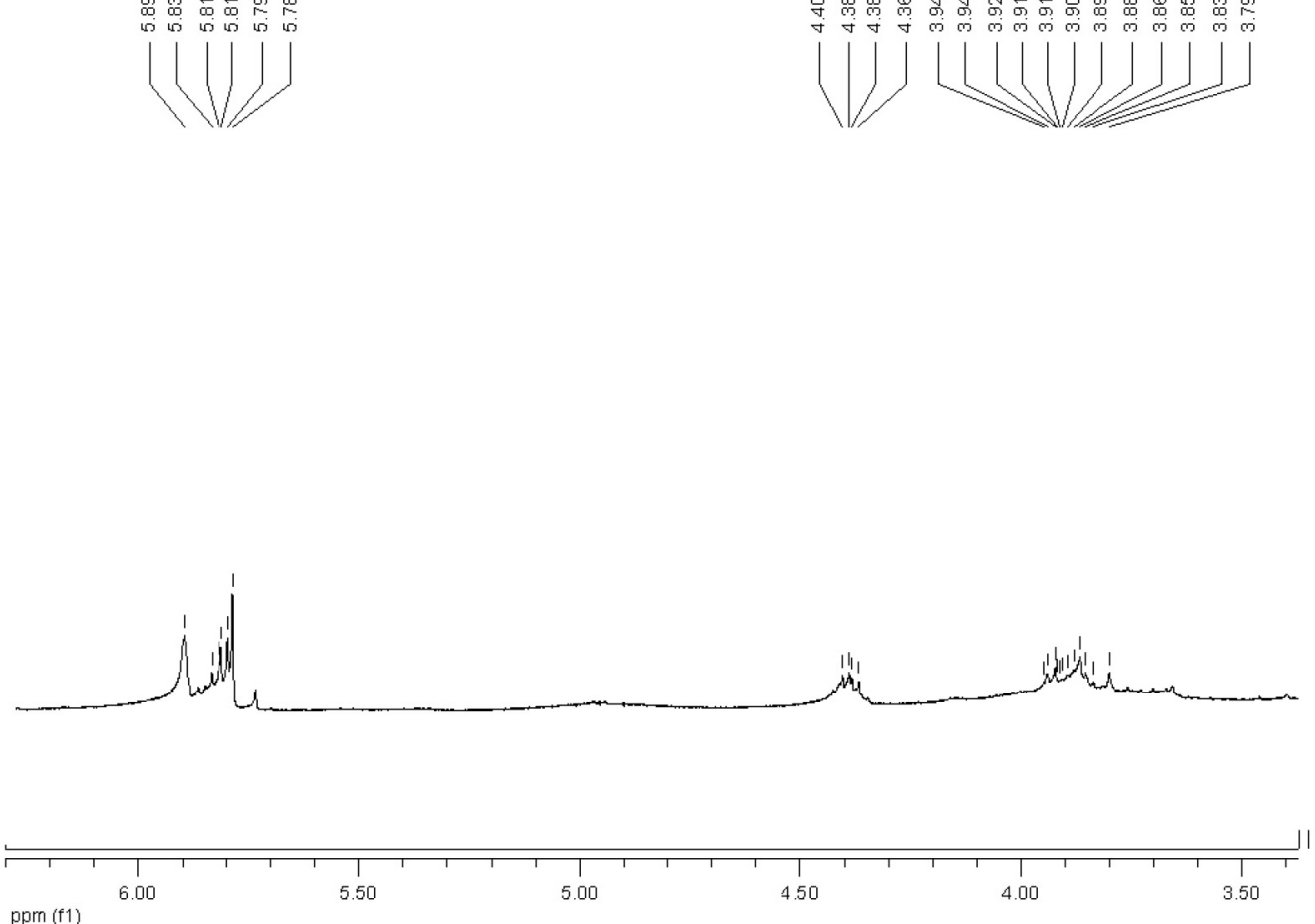

ppm (f1)

Figure S14. Expansion of ${ }^{1} \mathrm{H}$ NMR spectrum of compound $2\left(\mathrm{CDCl}_{3}, 300 \mathrm{MHz}\right)$.
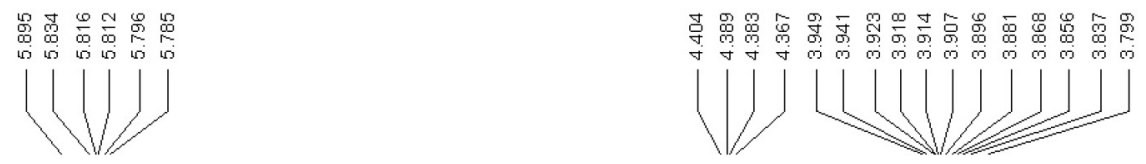

$\frac{120}{220}$
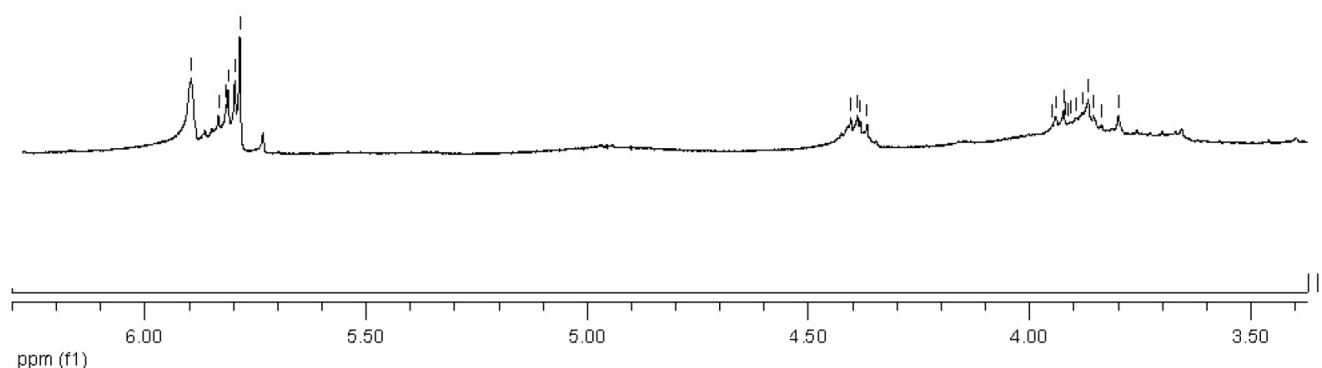

ppm (f1)

Figure S15. ${ }^{13} \mathrm{C}$ NMR spectrum of compound $2\left(\mathrm{CDCl}_{3}, 75 \mathrm{MHz}\right)$. 

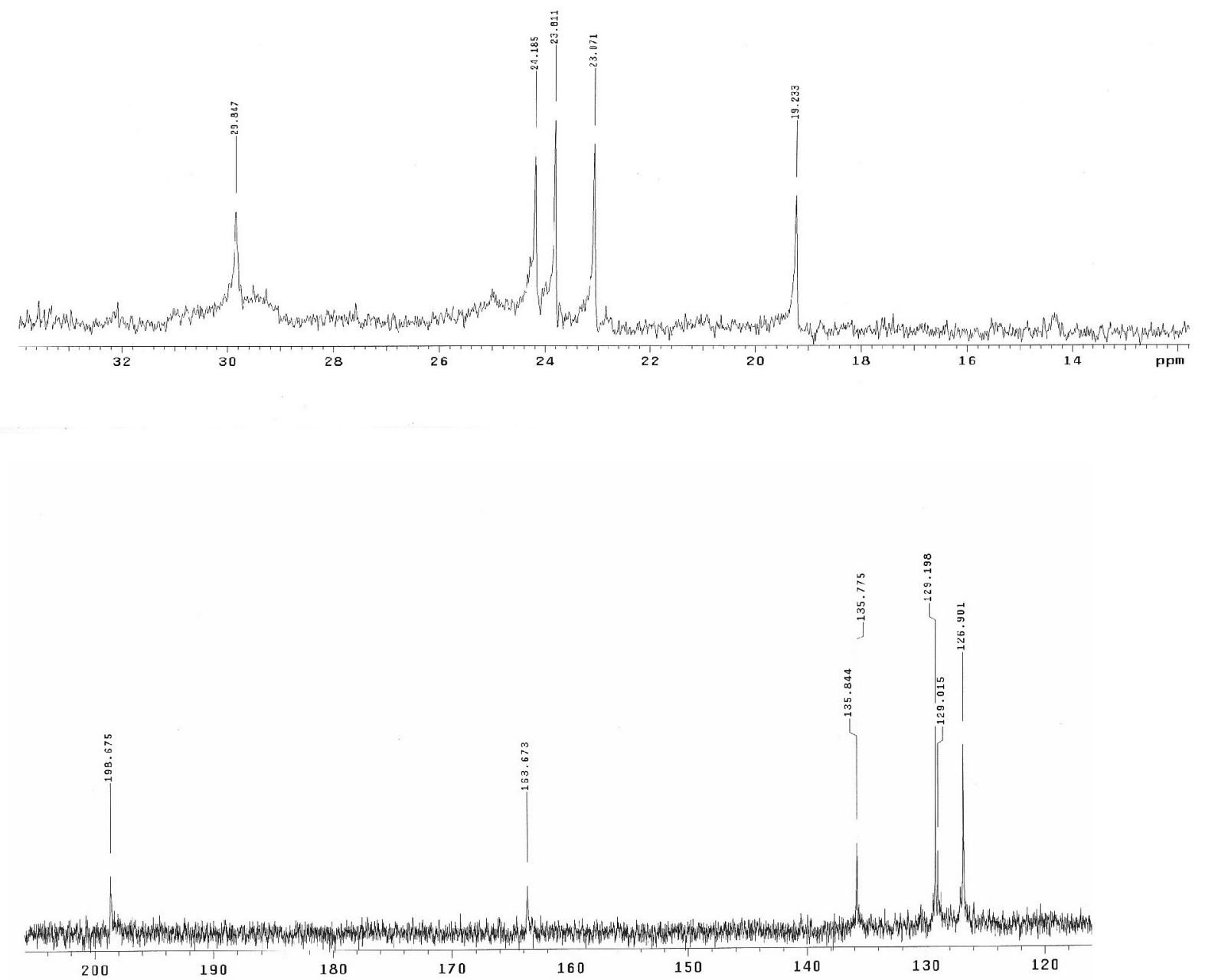

Figure S16. Expansion of ${ }^{13} \mathrm{C}$ NMR spectrum of compound $2\left(\mathrm{CDCl}_{3}, 75 \mathrm{MHz}\right)$.

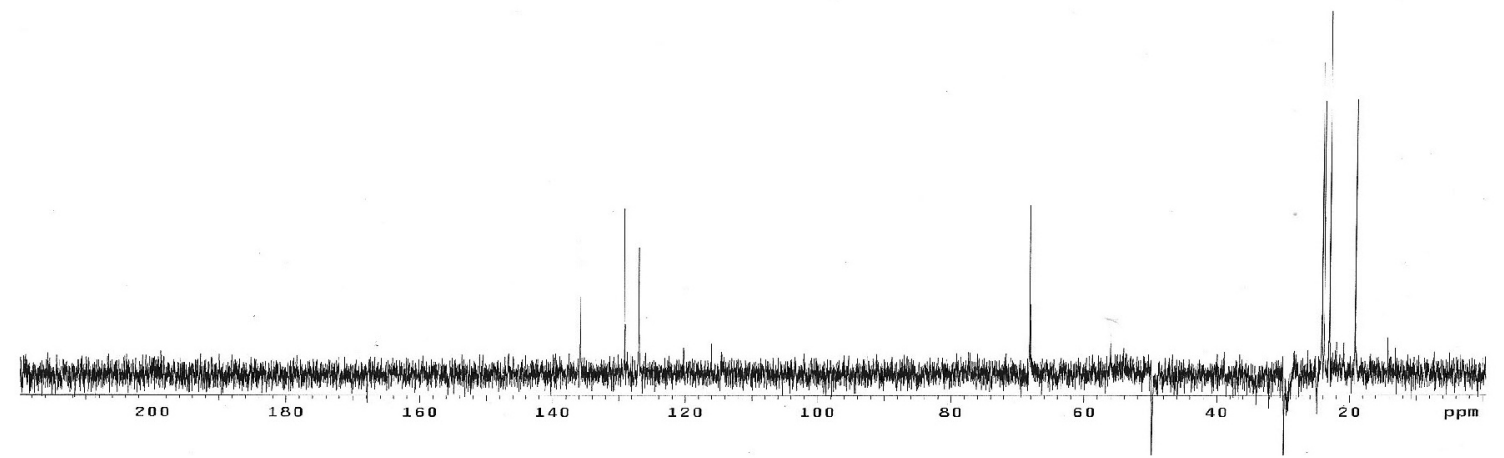

Figure S17. DEPT $135^{\circ}$ spectrum of compound $2\left(\mathrm{CDCl}_{3}, 75 \mathrm{MHz}\right)$. 
A

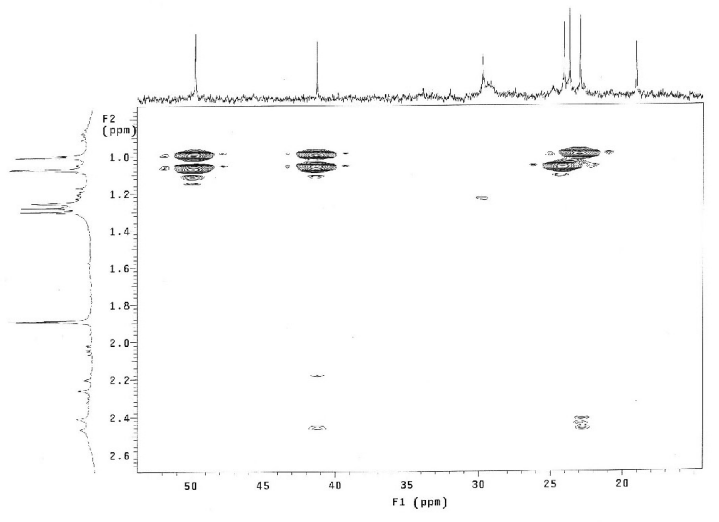

B

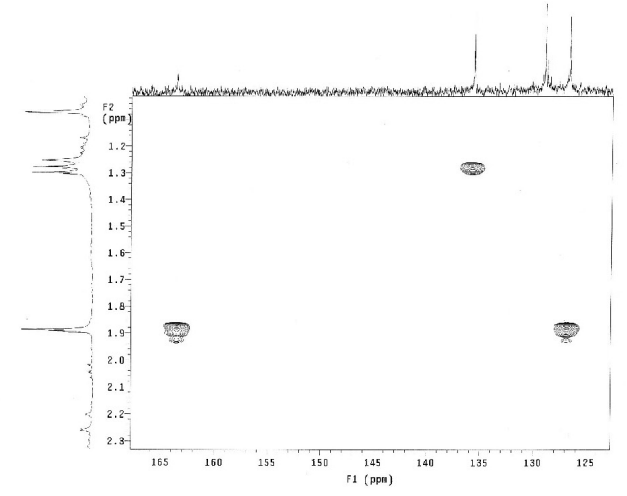

Figure S18. Expansion of the $g \mathrm{HMBC}$ spectrum compound 2.

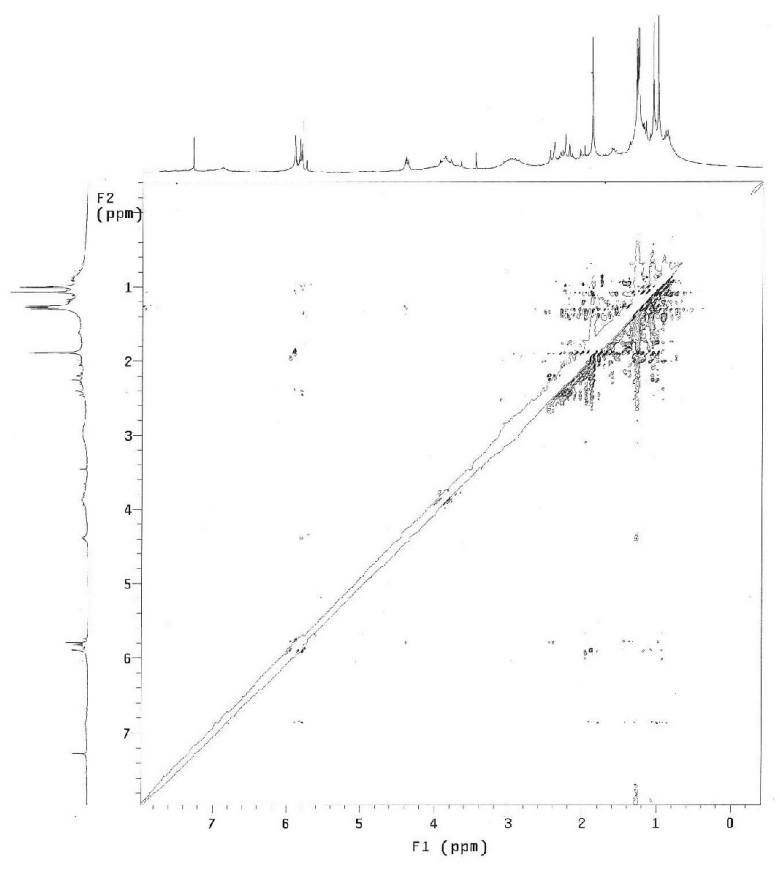

Figure S19. NOESY spectrum compound 2.

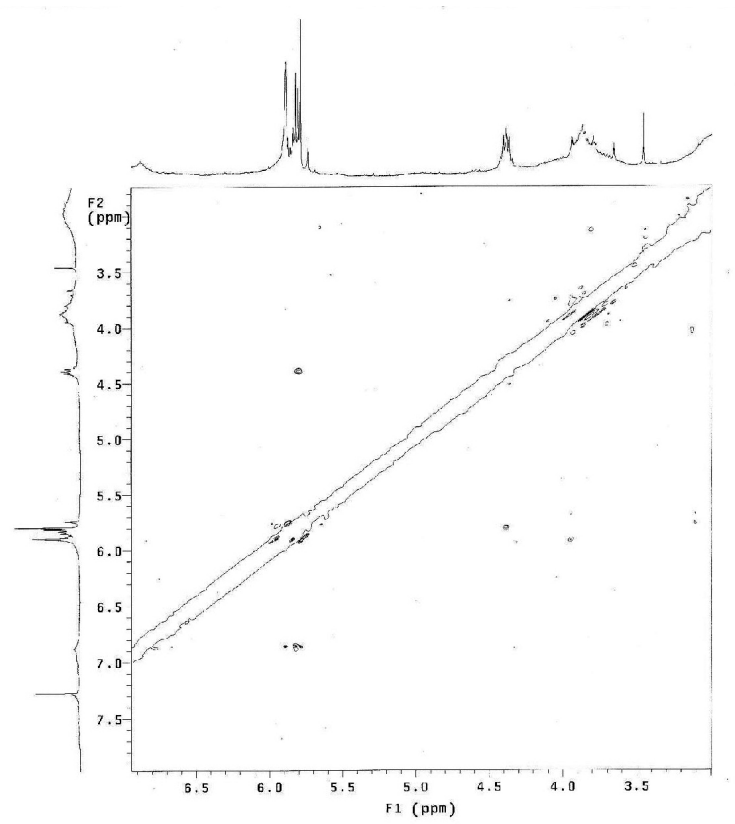

Figure S20. Expansion of the NOESY spectrum compound 2. 

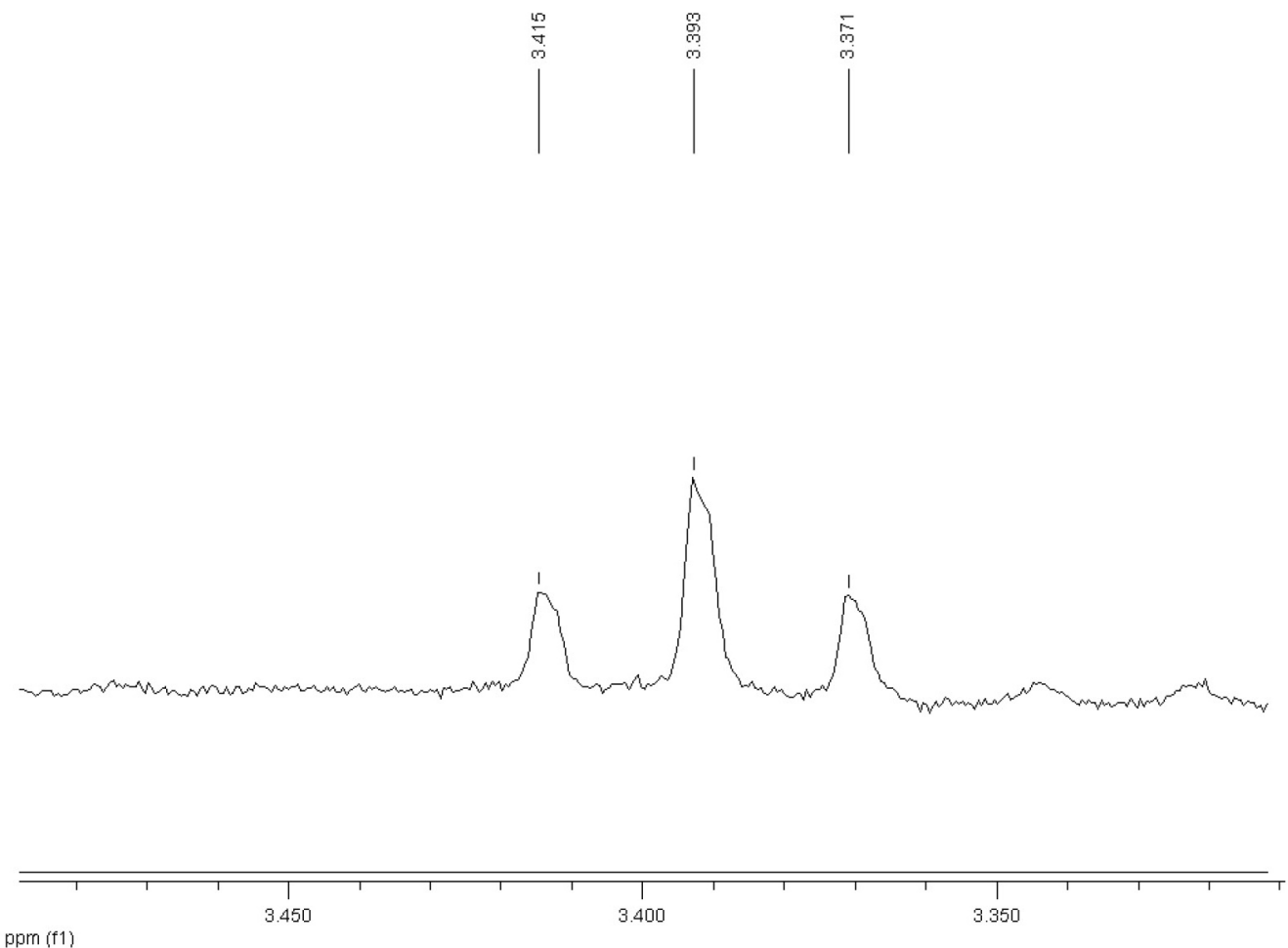

ppm (f1)

Figure S21. Expansion of ${ }^{1} \mathrm{H}$ NMR spectrum of product reduction of compound $2\left(\mathrm{C}_{5} \mathrm{D}_{4} \mathrm{~N}, 300 \mathrm{MHz}\right)$.

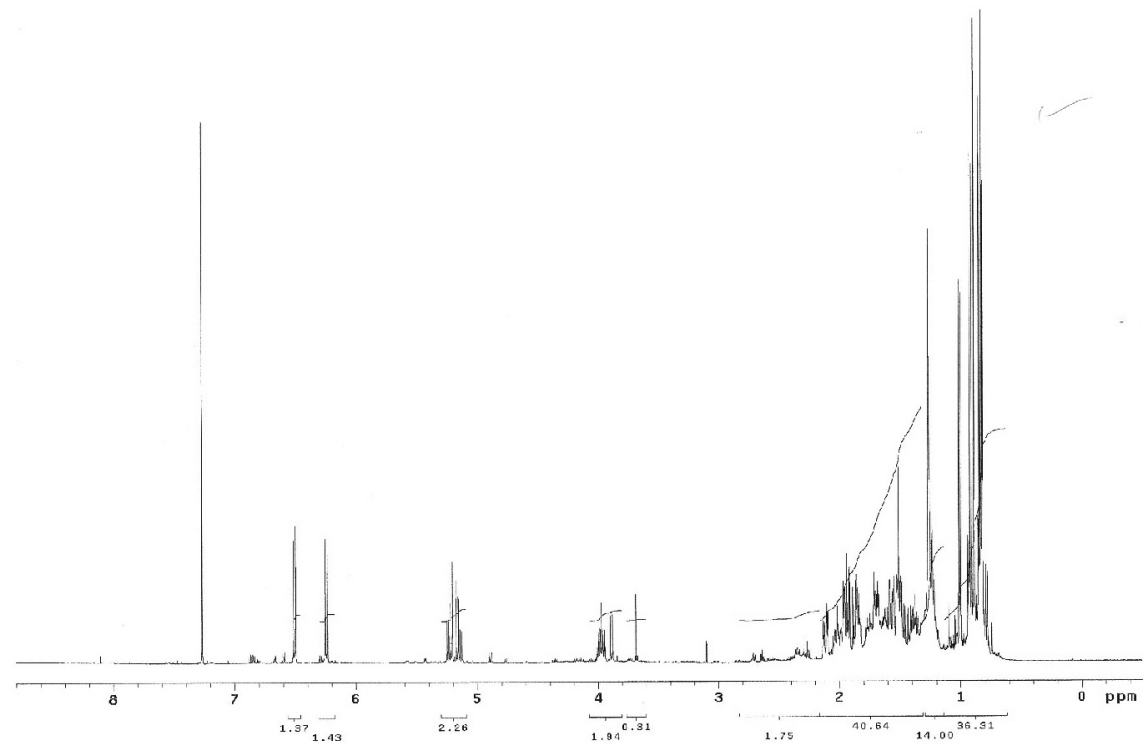

Figure S22. ${ }^{1} \mathrm{H}$ NMR spectrum of compound $\mathbf{3}\left(\mathrm{CDCl}_{3}, 500 \mathrm{MHz}\right)$. 

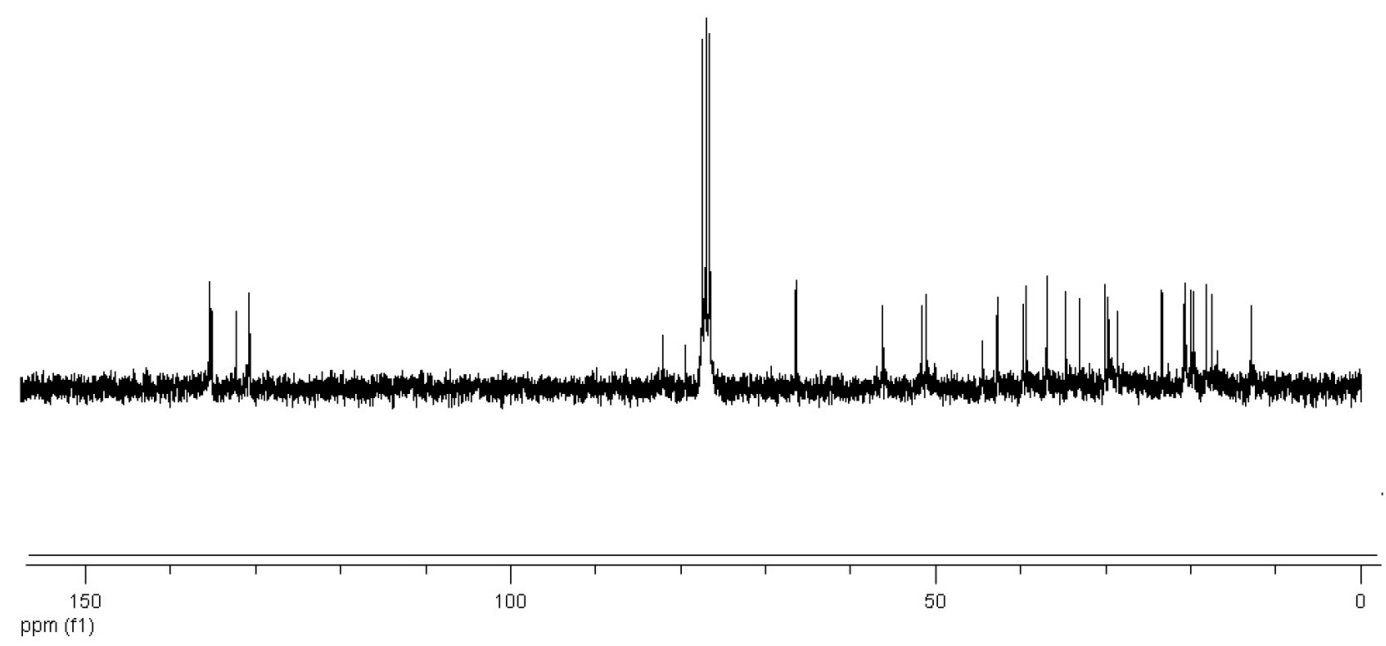

Figure S23. ${ }^{13} \mathrm{C}$ NMR spectrum of compound $\mathbf{3}\left(\mathrm{CDCl}_{3}, 75 \mathrm{MHz}\right)$.

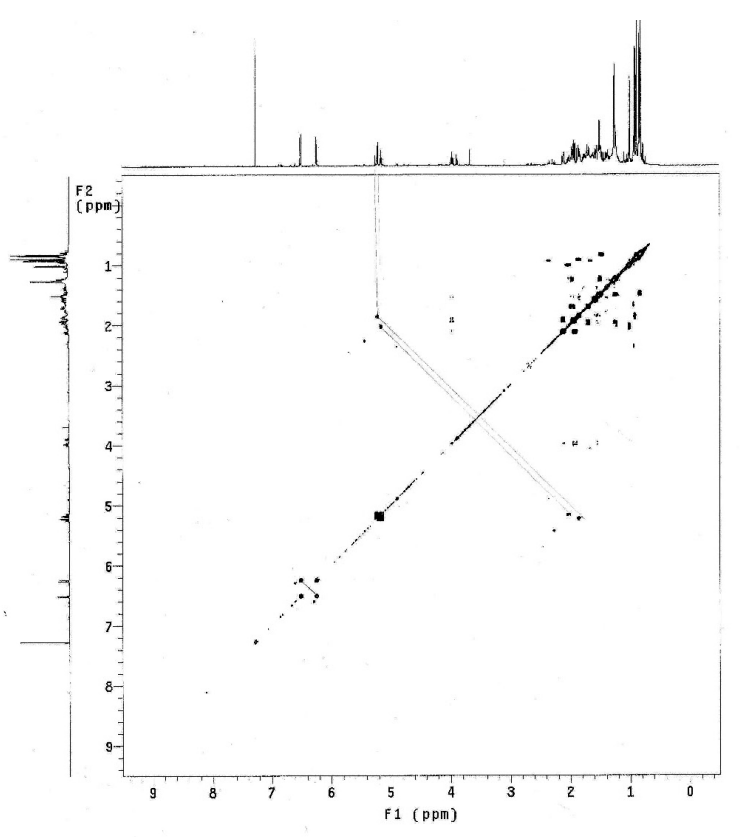

Figure S24. COSY of compound $\mathbf{3}\left(\mathrm{CDCl}_{3}, 500 \mathrm{MHz}\right)$.

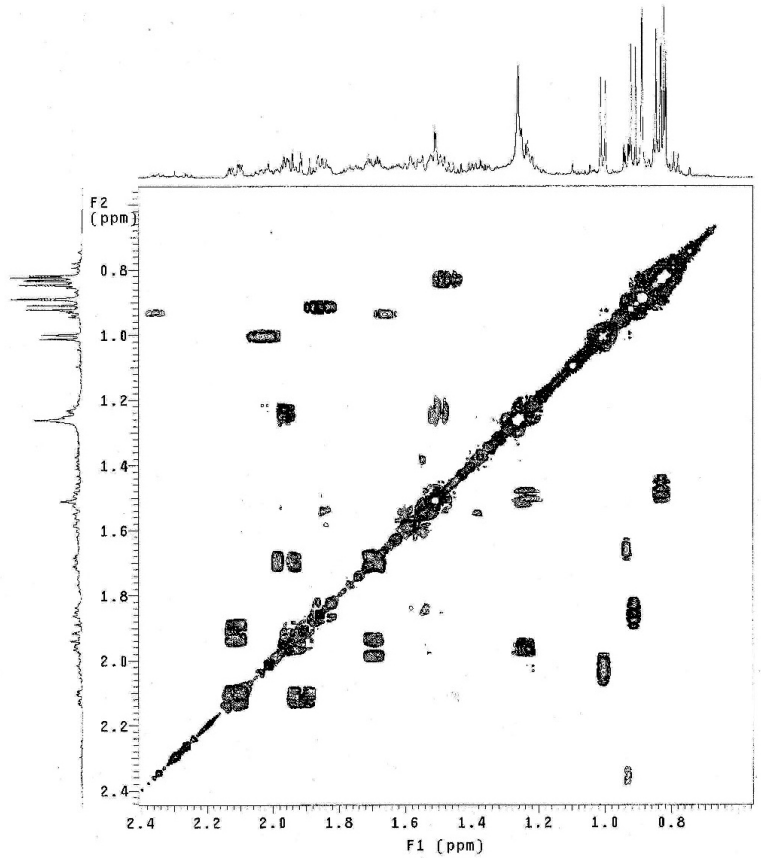

Figure S25. gHSQC of compound $\mathbf{3}\left(\mathrm{CDCl}_{3}\right)$. 
Vol. 20, No. 10, 2009

Lima et al.

$\mathrm{S} 13$

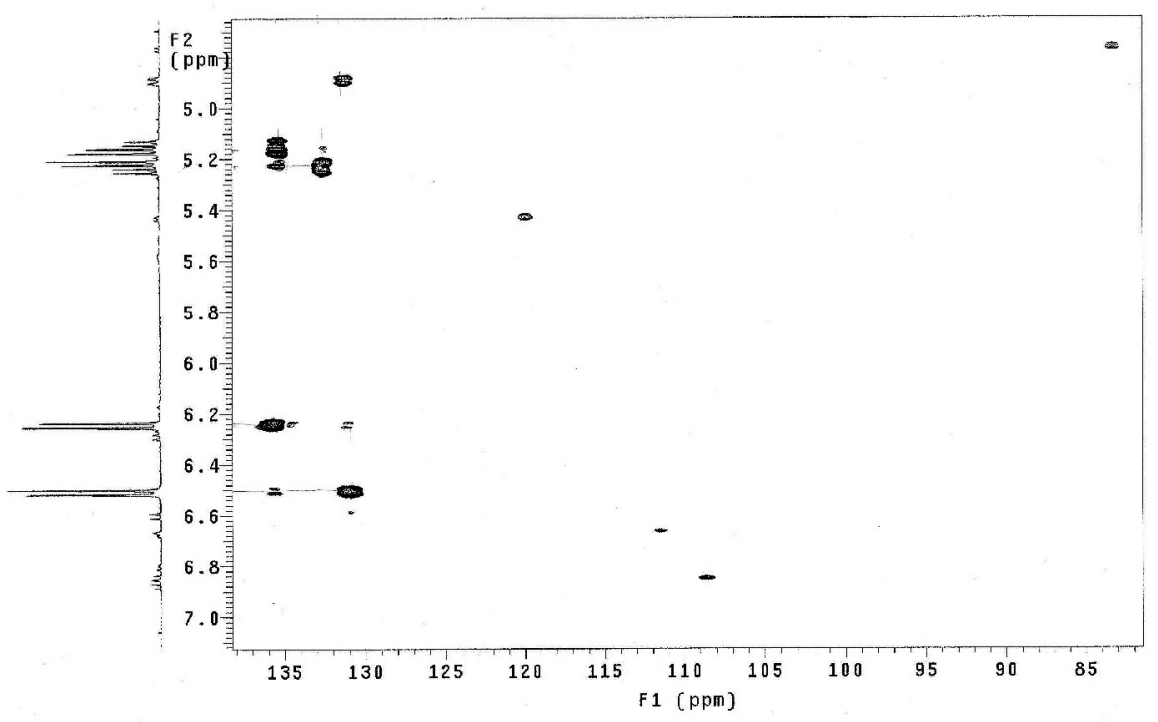

Figure S26. Expansion of gHSQC of compound $\mathbf{3}\left(\mathrm{CDCl}_{3}\right)$.

$: \mathbf{c}$

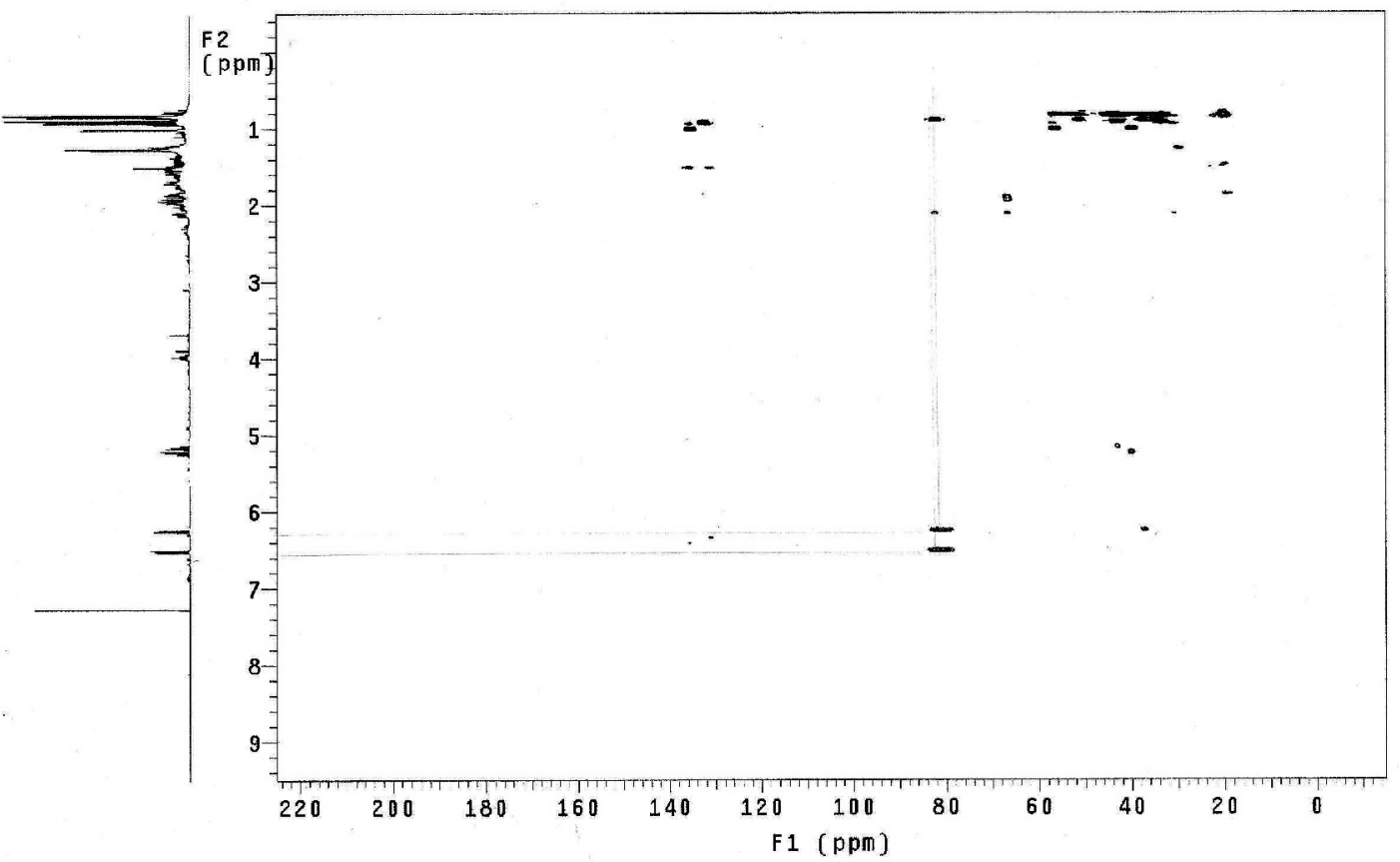

Figure S27. gHMBC of compound $\mathbf{3}\left(\mathrm{CDCl}_{3}\right)$. 


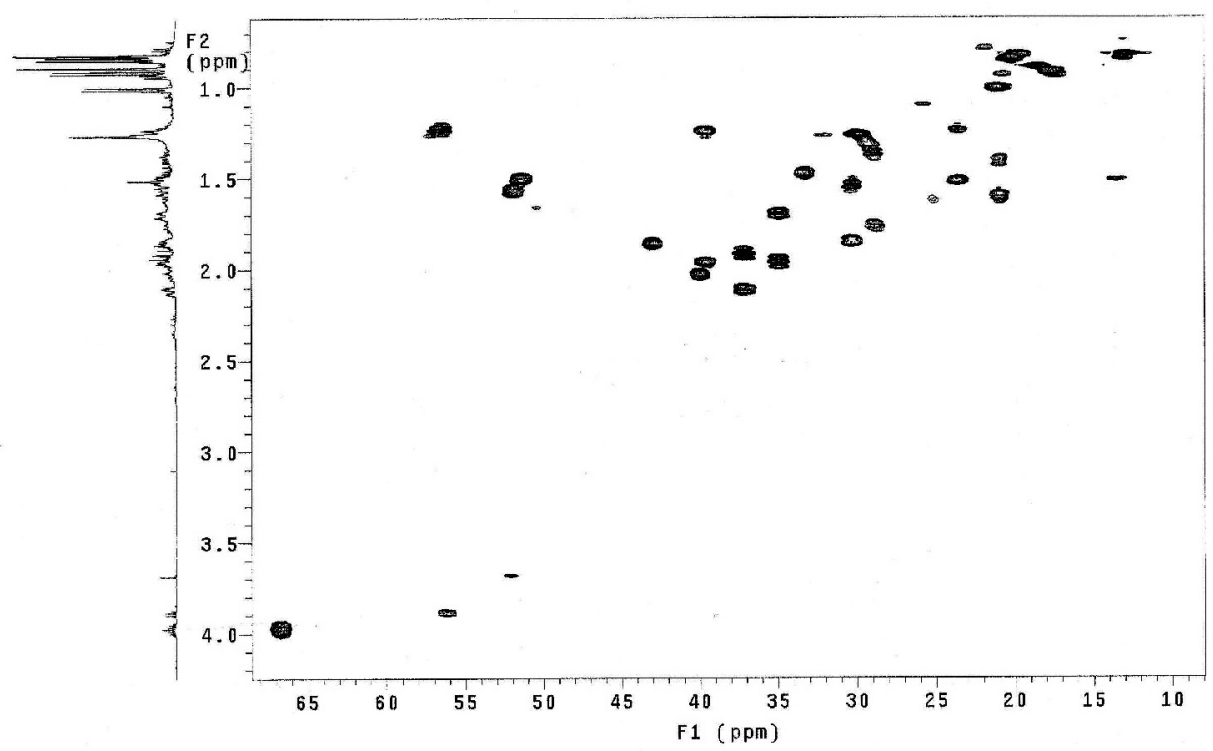

Figure S28. gHSQC of compound $\mathbf{3}\left(\mathrm{CDCl}_{3}\right)$.

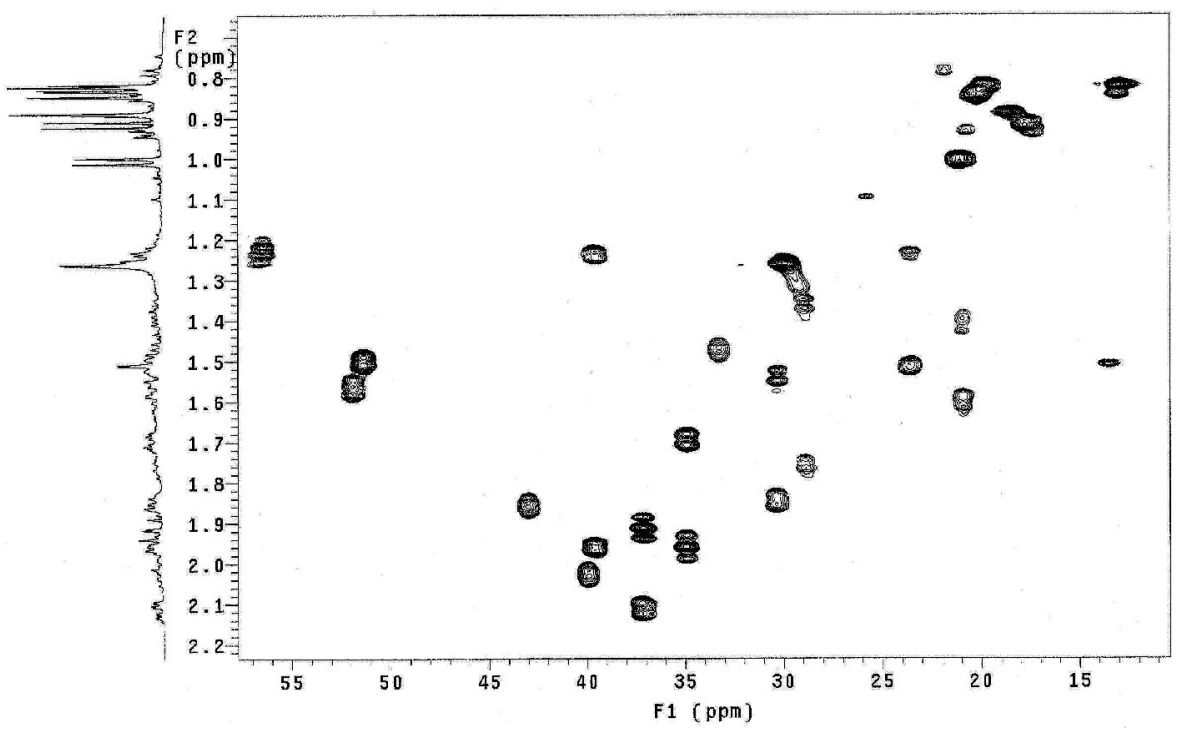

Figure S29. Expansion of gHSQC of compound $\mathbf{3}\left(\mathrm{CDCl}_{3}\right)$.

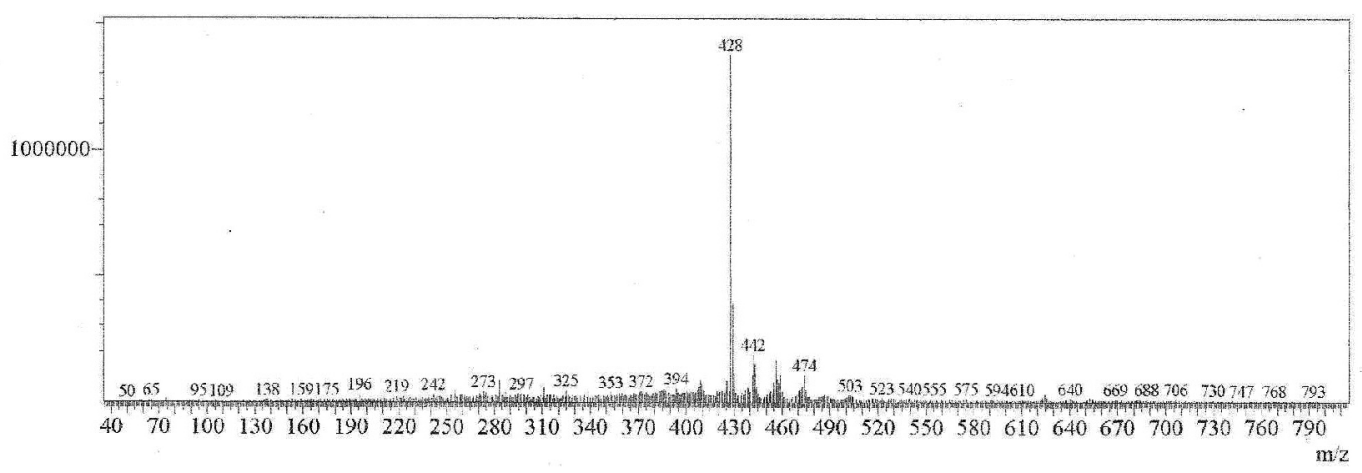

Figure S30. Negative ESIMS of compound 3. 